\title{
Envisat MIPAS measurements of CFC-11: retrieval, validation, and climatology
}

\author{
L. Hoffmann ${ }^{1}$, M. Kaufmann ${ }^{1}$, R. Spang ${ }^{1}$, R. Müller ${ }^{1}$, J. J. Remedios ${ }^{2}$, D. P. Moore ${ }^{2}$, C. M. Volk ${ }^{3}$, T. von Clarmann ${ }^{4}$, \\ and M. Riese ${ }^{1}$ \\ ${ }^{1}$ Forschungszentrum Jülich, Institut für Chemie und Dynamik der Geosphäre (ICG-1), Jülich, Germany \\ ${ }^{2}$ EOS, Space Research Centre, Department of Physics and Astronomy, University of Leicester, Leicester, UK \\ ${ }^{3}$ J. W. Goethe-Universität Frankfurt, Institut für Atmosphäre und Umwelt, Frankfurt, Germany \\ ${ }^{4}$ Forschungszentrum Karlsruhe, Institut für Meteorologie and Klimaforschung, Karlsruhe, Germany
}

Received: 1 November 2007 - Published in Atmos. Chem. Phys. Discuss.: 4 March 2008

Revised: 28 May 2008 - Accepted: 12 June 2008 - Published: 10 July 2008

\begin{abstract}
From July 2002 to March 2004 the Michelson Interferometer for Passive Atmospheric Sounding (MIPAS) aboard the European Space Agency's Environmental Satellite (Envisat) measured nearly continuously mid infrared limb radiance spectra. These measurements are utilised to retrieve the global distribution of the chlorofluorocarbon CFC11 by applying a new fast forward model for Envisat MIPAS and an accompanying optimal estimation retrieval processor. A detailed analysis shows that the total retrieval errors of the individual CFC-11 volume mixing ratios are typically below $10 \%$ in the altitude range 10 to $25 \mathrm{~km}$ and that the systematic components dominate. Contribution of a priori information to the retrieval results are less than 5 to $10 \%$ and the vertical resolution of the observations is about 3 to $4 \mathrm{~km}$ in the same vertical range. The data are successfully validated by comparison with several other space experiments, an airborne in-situ instrument, measurements from ground-based networks, and independent Envisat MIPAS analyses. The retrieval results from 425000 Envisat MIPAS limb scans are compiled to provide a new climatological data set of CFC11 . The climatology shows significantly lower CFC-11 abundances in the lower stratosphere compared with the Reference Atmospheres for MIPAS (RAMstan V3.1) climatology. Depending on the atmospheric conditions the differences between the climatologies are up to 30 to $110 \mathrm{ppt}$ (45 to $150 \%$ ) at 19 to $27 \mathrm{~km}$ altitude. Additionally, time series of CFC11 mean abundance and variability for five latitudinal bands are presented. The observed CFC-11 distributions can be
\end{abstract}

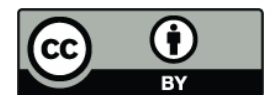

Correspondence to: L. Hoffmann (1.hoffmann@fz-juelich.de) explained by the residual mean circulation and large-scale eddy-transports in the upper troposphere and lower stratosphere. The new CFC-11 data set is well suited for further scientific studies.

\section{Introduction}

Monitoring the global distribution of chlorofluorocarbons like CFC-11 $\left(\mathrm{CFCl}_{3}\right)$ is important for several reasons. First, the chlorine released by photolytic decomposition in the stratosphere plays a major role in ozone depletion both in the upper stratosphere and in the polar regions (e.g. Solomon, 1999). Second, CFCs and most of their replacements are strong infrared absorbers, and they contribute significantly to the anthropogenic greenhouse effect (e.g. IPCC, 2007).

Less vital but more practical reasons to measure CFC-11 global distributions are: Continuous measurements of photochemically long-lived trace gases such as CFC-11 are useful to validate transport in atmospheric models (e.g. Golombek and Prinn, 1986; Kao et al., 1992; Hartley et al., 1996). Further, tracer-tracer relations of long-lived trace gases, e.g. between CFC-11 and $\mathrm{N}_{2} \mathrm{O}$, are frequently examined to identify mixing events (e.g. Plumb et al., 2000; Müller et al., 2001; Morgenstern et al., 2002). Data are also used for studies of age of air (e.g. Waugh et al., 2003).

CFC-11 has rather strong and broad spectral infrared emission features and is well suited for space-borne remote sensing observations (e.g. Zander et al., 1996; Bingham et al., 1997; Riese et al., 1999a; Yokota et al., 2002; Coheur et al., 2003; Kuell et al., 2005). Space measurements provide excellent global coverage but are less precise than in-situ

Published by Copernicus Publications on behalf of the European Geosciences Union. 
measurements. Validation of the space measurements is possible with a large number of ground-based and air-borne measurement techniques (e.g. Notholt, 1994; Elkins et al., 1996; Prinn et al., 2000; Blake et al., 2001).

In this paper we discuss a retrieval of CFC-11 global distributions from measurements by the Envisat MIPAS satellite experiment utilising a new fast forward model and optimal estimation retrieval processor developed in Jülich. The forward model utilises the emissivity growth approximation (EGA) to significantly accelerate the radiative transfer calculations. Envisat MIPAS radiance measurements are spectrally averaged for the retrieval, effectively synthesising a filter radiometer. This represents a significant difference from the approach used by other groups, i.e. using measurements at their full spectral sampling and monochromatic forward models.

The advantage of the EGA-technique is speed. Hence, it is especially suited for comprehensive analysis of infrared remote-sensing measurements from satellite missions. EGAbased forward models have been used for operational data processing for several satellite experiments (e.g. CLAES, HALOE, CRISTA, SABER, and HIRDLS). Since the European Space Agency (ESA) provides consolidated and validated Envisat MIPAS retrieval data for temperature and six major trace gases, we do not attempt to create a retrieval system that entirely replaces this work. We try to complement the ESA data with comprehensive datasets of minor trace species not covered by the operational analysis that will be of particular interest for scientific users.

The Envisat MIPAS instrument is briefly introduced in Sect. 2. Section 3 gives an overview of forward modelling for Envisat MIPAS and provides a detailed discussion of the retrieval process and results. Section 4 summarises multiple validation activities, carried out to ensure high quality of the retrieved CFC-11 data set. Finally, Sect. 5 presents a new CFC-11 climatology derived from the Envisat MIPAS measurements as well as a discussion of seasonal variability of CFC-11 during the time period July 2002 to March 2004.

\section{The Envisat MIPAS experiment}

On 1 March 2002 the European Space Agency (ESA) launched the Environmental Satellite (Envisat) (Louet, 2001; Dubock et al., 2001) from the space airport at Kourou, French Guiana. The satellite operates at $800 \mathrm{~km}$ altitude in a nearly polar, sun-synchronous orbit with $98.55^{\circ}$ inclination and $100 \mathrm{~min}$ period. Global coverage is achieved during 14.4 orbits per day. Ten scientific instruments aboard Envisat monitor the global state of the Earth system and environment.

The Michelson Interferometer for Passive Atmospheric Sounding (MIPAS) (Fischer and Oelhaf, 1996; Endemann, 1999; Fischer et al., 2008) is one of the atmospheric experiments aboard Envisat. Envisat MIPAS provided nearly continuous measurement coverage for the period July 2002 to
March 2004. Due to an unexpected technical problem with the interferometer slides in March 2004, the instrument was operated at a reduced spectral resolution and in a campaignorientated mode till February 2007. It is now operating continuously again with reduced spectral resolution and a new spatial scanning sequence. In this paper we analyse measurements obtained during the first two years of operation where consolidated Level-1B and Level-2 data products are available from ESA (processing software version 4.61 and 4.62).

Envisat MIPAS measures the mid infrared thermal emission of atmospheric constituents arising from the limb. Spectral measurements cover the range 685 to $2410 \mathrm{~cm}^{-1}$ in five radiance channels. The unapodised spectral resolution of the interferometer was about $0.03 \mathrm{~cm}^{-1}$ in the first two years of continuous operation.

The original nominal measurement mode of Envisat MIPAS covered 17 tangent heights in the vertical range 6 to $68 \mathrm{~km}$. The nominal vertical sampling step was $3 \mathrm{~km}$ from the troposphere to the mid stratosphere and increased to 5 to $8 \mathrm{~km}$ above this. The instantaneous field of view covers approximately $3 \times 30 \mathrm{arcmin}^{2}$, corresponding to $3 \times 30 \mathrm{~km}^{2}$ in vertical and horizontal extent at the tangent point, respectively. The measurement time for a single spectrum was about $4 \mathrm{~s}$. A full vertical limb scan required $75 \mathrm{~s}$. The horizontal distance between two profiles was about $500 \mathrm{~km}$. During one day Envisat MIPAS measured about 1100 vertical profiles.

Measurements from Envisat MIPAS are processed in different steps. The aim of the ESA operational Level-0 to Level-1B data processing is the conversion of instrument raw data to calibrated radiance spectra with corresponding geolocation data. The main steps involved are quality checks of raw data, phase correction and Fourier-transformation of raw interferograms, radiometric calibration, spectral calibration, and evaluation of satellite and instrument attitude data (Lachance, 1999; Nett, 1999; Kleinert et al., 2007). Within the ESA Level-2 processing vertical profiles of several atmospheric parameters are derived from the radiance measurements (Ridolfi et al., 2000; Carlotti et al., 2001; Carli et al., 2004; Raspollini et al., 2006). Target parameters of the ESA operational retrievals are pressure, temperature, and volume mixing ratios of six target species $\left(\mathrm{H}_{2} \mathrm{O}, \mathrm{O}_{3}, \mathrm{HNO}_{3}, \mathrm{CH}_{4}\right.$, $\mathrm{N}_{2} \mathrm{O}, \mathrm{NO}_{2}$ ). However, the ESA Level-2 processing does not include many minor trace species, e.g. the CFCs, that are covered as well by the radiance measurements.

Comprehensive pre-flight and routine in-flight calibrations were carried out to guarantee a high quality Envisat MIPAS Level-1B data product (e.g. Nett et al., 2002; Kleinert et al., 2007; Kiefer et al., 2007). Envisat MIPAS atmospheric data products have been validated by detailed tests of selfconsistency as well as by comparison with measurements obtained by independent in-situ and other remote-sensing experiments (e.g. Piccolo and Dudhia, 2007; Ridolfi et al., 2007). 


\section{Retrieval of CFC-11 abundance}

\subsection{Forward modelling}

In the mid infrared CFC-11 strongly radiates in the $v_{4}$ band at 800 to $885 \mathrm{~cm}^{-1}$ with a band strength of about $6.5 \times 10^{-17} \mathrm{~cm}^{2} /(\operatorname{molec} \mathrm{cm})$ at $293 \mathrm{~K}$ and the $\nu_{1}$ band at 1045 to $1120 \mathrm{~cm}^{-1}$ with a band strength of about $2.5 \times 10^{-17} \mathrm{~cm}^{2} /(\operatorname{molec} \mathrm{cm})$ at $293 \mathrm{~K}$ (e.g. McDaniel et al., 1991; Varansi, 1991). The $v_{2}+v_{3}$ combination band weakly emits at 910 to $960 \mathrm{~cm}^{-1}$ with a band strength of $0.17 \times 10^{-17} \mathrm{~cm}^{2} /($ molec $\mathrm{cm})$ at $293 \mathrm{~K}$. The $\nu_{2}+\nu_{3}$ combination band is too weak for a retrieval analysis and spectroscopic data are not provided in the High Resolution Transmission (HITRAN) compilation (Rothman et al., 2003).

Several schemes to identify optimal spectral analysis windows have been proposed, which all aim at minimisation of the retrieval error, or equivalently, the maximisation of the Shannon information content (e.g. Rodgers, 1998; von Clarmann and Echle, 1998; Dudhia et al., 2002). In our case, the Shannon information content under consideration of MIPAS instrument errors (e.g. noise and uncertainties in radiometric calibration) as well as forward model parameter errors (e.g. uncertainties in pressure, temperature, or interfering species) was chosen as figure of merit to be optimised. The spectral window 844.275 to $850.575 \mathrm{~cm}^{-1}$ was identified as being best suited for the retrieval of CFC-11 from the Envisat MIPAS measurements (Fig. 1). The optimisation is carried out for mid-latitude atmospheric conditions, however tests for other climatological conditions (tropics or polar regions) lead to only minor changes in the obtained optimal spectral window.

To allow for a complete analysis of all radiance measurements made by Envisat MIPAS and the subsequent comprehensive compilation of CFC-11 climatological data we utilise a new fast radiative transfer forward model. The Juelich Rapid Spectral Simulation Code (JURASSIC) (Hoffmann, 2006) computes the radiative transfer based on the band transmittance approximation, the continuum approximation, and the emissivity growth approximation (EGA) (Weinreb and Neuendorffer, 1973; Gordley and Russel, 1981; Marshall et al., 1994; Francis et al., 2006).

A major reduction of CPU-time is achieved in JURASSIC, because the radiative transfer is not computed based on the general monochromatic approach, but by operating on spectral mean values of emissivity, Planck function, and radiance instead. The mean values calculated by the forward model are those of the spectral windows used for the retrieval. Spectral mean emissivities are obtained by interpolation from precomputed look-up-tables. The emissivity look-up-tables are derived from exact line-by-line calculations, utilising the MIPAS Reference Forward Model (RFM) (Dudhia, 2004). As an example, Fig. 2 shows the results of a typical JURASSIC forward calculation for mid-latitude atmospheric conditions.

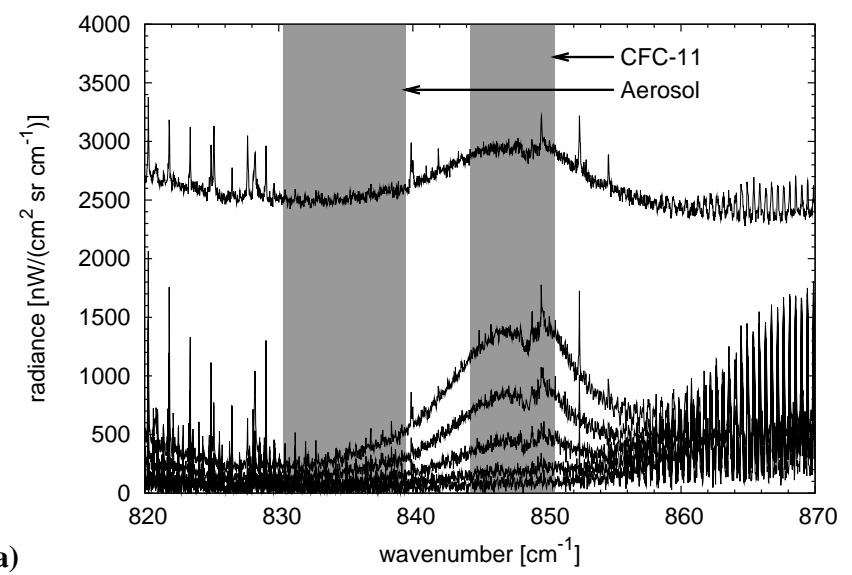

(a)

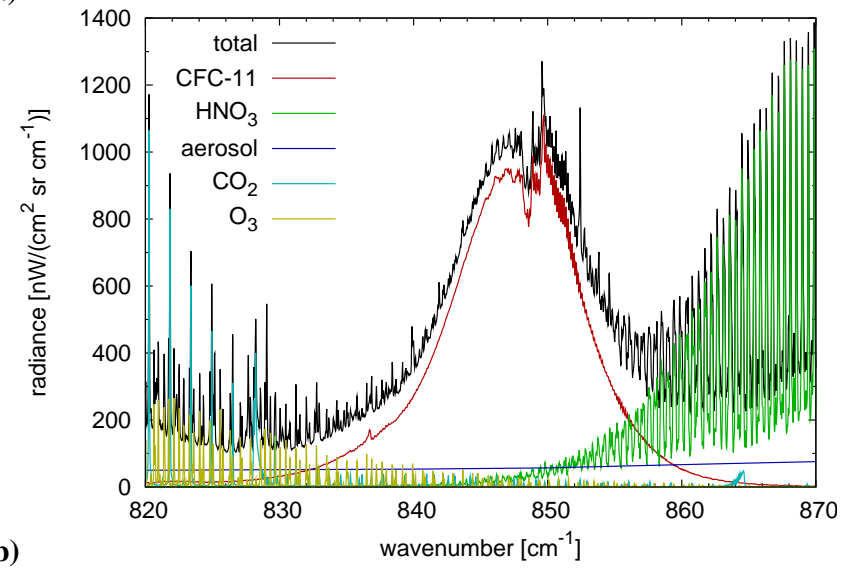

Fig. 1. (a) Envisat MIPAS radiance measurements obtained on 5 November 2003, 07:30 UTC near $42^{\circ} \mathrm{E}, 67^{\circ} \mathrm{N}$. Tangent heights from top to bottom are $7.4 \mathrm{~km}, 10.3 \mathrm{~km}, 13.2 \mathrm{~km}, 16.2 \mathrm{~km}, 19.1 \mathrm{~km}$, and $22.1 \mathrm{~km}$. The spectrum for the lowermost tangent height contains a strong radiometric background due to cloud emissions. Grey shaded areas indicate spectral windows used for the retrieval. (b) Simulated Envisat MIPAS radiance spectra for $12 \mathrm{~km}$ tangent height and mid latitude atmospheric conditions.

For the spectral windows used in the CFC-11 retrieval, the difference in CPU time required on a conventional workstation by JURASSIC and the RFM is about three orders of magnitude. However, the approximations lead to a small loss of accuracy, which is quantified by comparisons with exact line-by-line calculations. For the spectral windows utilised here, the deviations are well below $0.5 \%$ (Fig. 3) and are rather small compared to other uncertainties, e.g. spectroscopic data. Model errors above one percent were found only in the tropical mid troposphere, where the CFC-11 band gets optically thick.

Based on forward calculations of spectra for multiple atmospheric conditions, further studies were carried out to determine the radiance contributions of minor interfering trace species. For this purpose the radiance of an atmosphere containing one absorber only is compared with the radiance of an atmosphere containing all absorbers. For 


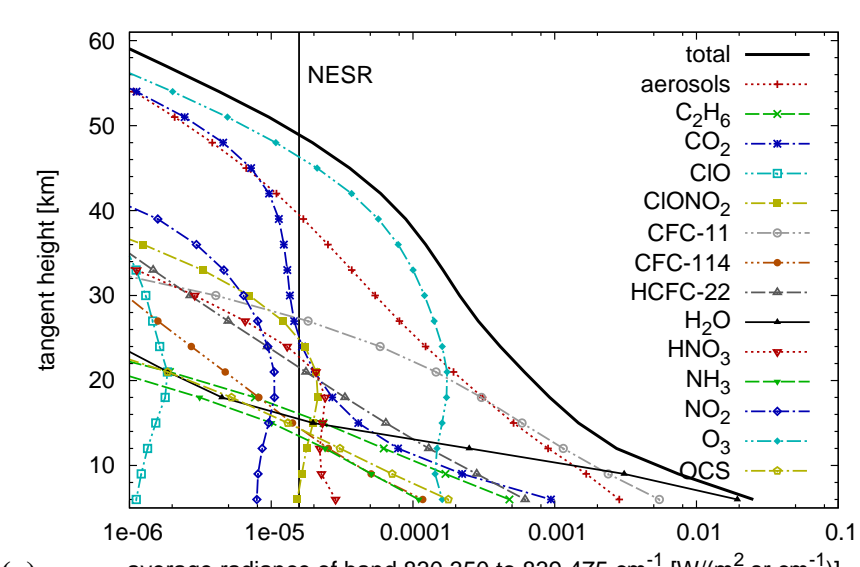

(a) average radiance of band 830.350 to $\left.839.475 \mathrm{~cm}^{-1}\left[\mathrm{~W} /\left(\mathrm{m}^{2} \mathrm{sr} \mathrm{cm}\right)^{-1}\right)\right]$

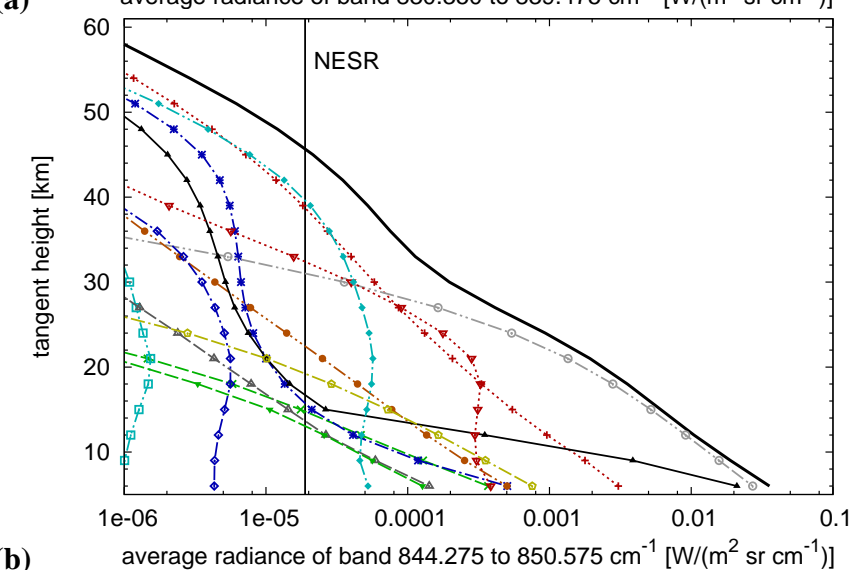

Fig. 2. MIPAS forward model simulations utilising the rapid radiative transfer model JURASSIC. Calculations are based on midlatitude atmospheric conditions and cover the spectral windows selected for the retrieval of (a) the total particle extinction and (b) the CFC-11 volume mixing ratios. The solid vertical lines indicate the corresponding Envisat MIPAS noise equivalent spectral radiance (NESR) for the spectral windows.

tangent heights in the range 10 to $40 \mathrm{~km}$, the maximum contributions to total mean radiance in the spectral window 844.275 to $850.575 \mathrm{~cm}^{-1}$ due to CFC-11 are up to $93 \%$. Other contributing species are $\mathrm{HNO}_{3}$ (up to $55 \%$ ), $\mathrm{O}_{3}(43 \%)$, background aerosols (36\%), $\mathrm{CO}_{2}(22 \%), \mathrm{H}_{2} \mathrm{O}(8.6 \%), \mathrm{NO}_{2}$ (5.7\%), CFC-114 (3.1\%), OCS (1.7\%), and $\mathrm{ClO}(1.1 \%)$. Any other trace gas contributes less than $1 \%$ to total mean radiance in all reference calculations. Since the maximum contributions are obtained at different heights and for different atmospheric conditions the percentages listed above do not total to $100 \%$.

The CFC-11 retrieval must be accompanied by a retrieval of radiometric background caused by aerosols, optically thin clouds, or other continuum processes. We identify the spectral window 830.350 to $839.475 \mathrm{~cm}^{-1}$ as being best suited for the retrieval of total particle extinction. Radiance contributions of the background aerosols are up to $45 \%$, but increase to over $90 \%$ if clouds are present. Other impor-

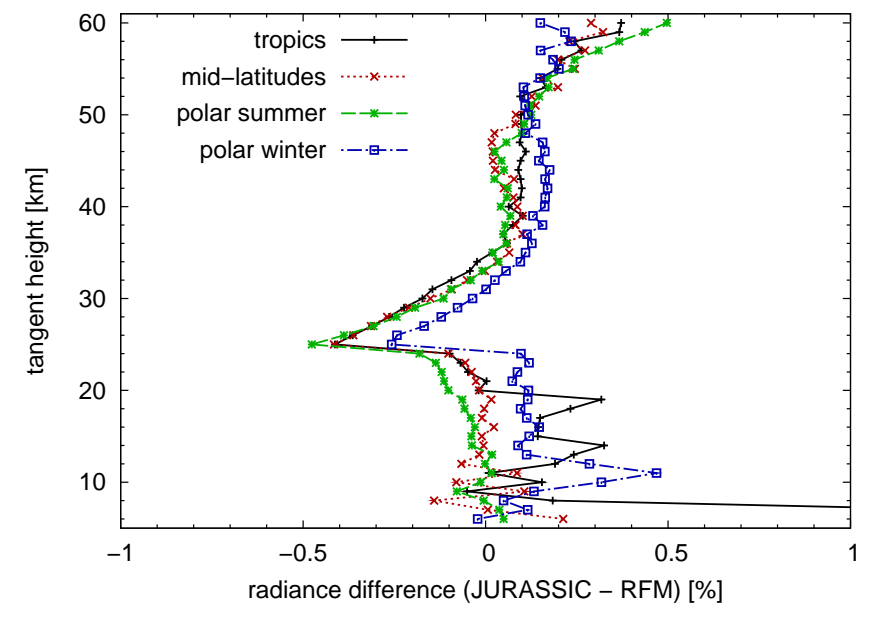

Fig. 3. Comparison of radiative transfer calculations based on the EGA method (JURASSIC) and line-by-line calculations (RFM) for different atmospheric conditions. Results are shown for the centre of the CFC-11 band ( 844.275 to $850.575 \mathrm{~cm}^{-1}$ ).

tant radiance emitters in this spectral window are $\mathrm{O}_{3}(69 \%)$, CFC-11 (56\%), $\mathrm{CO}_{2}(26 \%), \mathrm{ClONO}_{2}(12 \%), \mathrm{HNO}_{3}(7.8 \%)$, HCFC-22 (7.2\%), $\mathrm{NO}_{2}(5.2 \%), \mathrm{C}_{2} \mathrm{H}_{6}(3.5 \%), \mathrm{ClO}(3.1 \%)$, OCS (1.4\%), CFC-114 (1.4\%), $\mathrm{H}_{2} \mathrm{O}(1.4 \%), \mathrm{NH}_{3}(1.3 \%)$.

Since rather wide spectral windows are selected for the retrieval, high signal-to-noise ratios for the spectral mean radiances are obtained. In the 10 to $40 \mathrm{~km}$ altitude range the signal-to-noise ratio varies between 2.1 and 650 in the CFC11 spectral window $\left(844.275\right.$ to $\left.850.575 \mathrm{~cm}^{-1}\right)$. It varies between 3.1 and 190 for the continuum spectral window ( 830.350 to $839.475 \mathrm{~cm}^{-1}$ ). Due to the high signal-to-noise ratio at the lowermost altitudes noise becomes a minor source of error and the CFC-11 retrievals are more strongly influenced by other instrument errors or forward model parameter errors.

\subsection{Data pre-processing}

Important steps in data pre-processing are apodization and spectral averaging of the Envisat MIPAS radiance spectra. For apodization the "strong function" of Norton and Beer $(1976,1977)$ is applied. The apodized instrument lineshapes for the individual spectral grid points are required to derive exact radiometric filter functions for the forward model. Apodization is necessary to remove side-lobe effects at the boundaries of the radiometric filter functions. Please see Fig. 4 for an illustration.

Another important step in the pre-processing is cloud filtering. Spectra containing cloud emission (e.g. Fig. 1, lowermost tangent height) cannot be simulated with JURASSIC because scattering is neglected in the current version of the model. The cloud filtering algorithm of Spang et al. (2004) is based on the analysis of the so-called cloud index $(C I)$, which is defined as the ratio of mean radiances 
in the spectral windows 788.2 to $796.25 \mathrm{~cm}^{-1}$ and 832.3 to $834.4 \mathrm{~cm}^{-1}$. The long wavelength region is dominated by $\mathrm{CO}_{2}$ emission. The short wavelength region is part of an atmospheric window and is strongly influenced by aerosols or cloud particle emissions. In the presence of optically thin or thick clouds the $C I$ quickly drops below certain thresholds. In the ESA operational retrievals a threshold of $C I<1.8$ is used for cloud-filtering. We apply a more strict cloud filtering criterion to remove even optically thin clouds by using a threshold of $C I<4.0$ (e.g. Glatthor et al., 2006).

\subsection{Optimal estimation retrieval}

Retrieval is based on the standard optimal estimation approach (Rodgers, 1976, 1990, 2000). The "optimal estimate" of the atmospheric state (i.e. the maximum a posteriori solution of the inverse problem) is found by minimising the deviations between forward model simulations based on the current estimate of the state and the actual radiance measurements, as well as minimising the deviations between the estimate and the a priori state. Deviations are normalised by the measurement error covariance and the a priori covariance, respectively. The objective function to be minimised is

$$
J(\mathbf{x})=[\mathbf{y}-\mathbf{F}(\mathbf{x})]^{T} \mathbf{S}_{\epsilon}^{-1}[\mathbf{y}-\mathbf{F}(\mathbf{x})]+\left(\mathbf{x}-\mathbf{x}_{a}\right)^{T} \mathbf{S}_{a}^{-1}\left(\mathbf{x}-\mathbf{x}_{a}\right),
$$

where $\mathbf{x}$ denotes the state vector, $\mathbf{y}$ denotes the measurement vector, $\mathbf{F}$ denotes the forward model, $\mathbf{S}_{\epsilon}$ denotes the measurement covariance matrix, $\mathbf{x}_{a}$ denotes the a priori state vector, and $\mathbf{S}_{a}$ denotes the a priori covariance matrix. A multi-target approach is applied, i.e. all retrieval targets (CFC-11 volume mixing ratios and aerosol extinction coefficients) are derived simultaneously and correlations between the different quantities are fully taken into account in the retrieval covariance. The individual Envisat MIPAS tangent heights are used to define the retrieval grid.

Since the retrieval problem is moderately non-linear, a linear-search approach based on the Gauss-Newton method is used to find the minimum of the objective function iteratively,

$\mathbf{x}_{i+1}=\mathbf{x}_{i}+\gamma\left(\mathbf{K}_{i}^{T} \mathbf{S}_{\epsilon}^{-1} \mathbf{K}_{i}+\mathbf{S}_{a}^{-1}\right)^{-1}$

$\left\{\mathbf{K}_{i}^{T} \mathbf{S}_{\epsilon}^{-1}\left[\mathbf{y}-\mathbf{F}\left(\mathbf{x}_{i}\right)\right]-\mathbf{S}_{a}^{-1}\left(\mathbf{x}_{i}-\mathbf{x}_{a}\right)\right\}$,

where $i$ denotes the iteration index and $\mathbf{K}=\partial \mathbf{F}(\mathbf{x}) / \partial \mathbf{x}$ denotes the forward model Jacobian or the kernel matrix. The parameter $\gamma$ is used to scale the step size in state space. For the start value $\gamma=1$ a Gauss-Newton step is obtained. If an iterative step leads to an increase of $J$ rather than a decrease, the step size is reduced by $\gamma \rightarrow \gamma / 10$ and tested again. Convergence is tested for by analysing the scaled step size in state space,

$d_{i}^{2}=\left(\mathbf{x}_{i+1}-\mathbf{x}_{i}\right)^{T} \hat{\mathbf{S}}^{-1}\left(\mathbf{x}_{i+1}-\mathbf{x}_{i}\right) \ll n$,

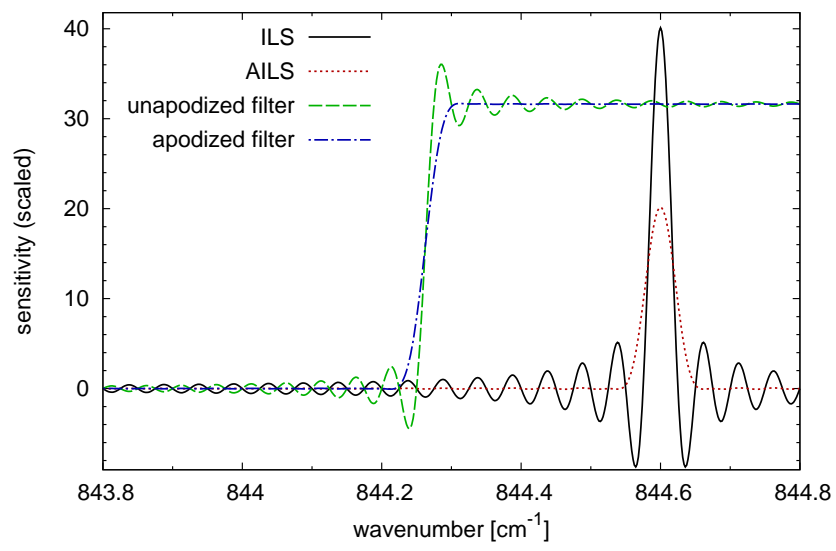

Fig. 4. Example for the theoretical instrument line shape (ILS, black curve) and apodized ILS (AILS, red curve) for one grid point $\left(844.6 \mathrm{~cm}^{-1}\right)$ of the Envisat MIPAS measurement spectrum. Filter functions for the spectral window 844.275 to $850.575 \mathrm{~cm}^{-1}$ are obtained by averaging all ILS or AILS within the window (green or blue curve, scaled by factor 200). The plot demonstrates that the filter function will have side-lobes at the boundary of the window $\left(844.275 \mathrm{~cm}^{-1}\right)$ if apodization is neglected.

where $\mathbf{S}^{-1}$ denotes the retrieval covariance matrix (i.e. its iterative estimate) and $n$ denotes the number of state vector elements. The actual test is carried out by testing $d_{i}^{2} / n \stackrel{?}{<}$ 0.1 .

The inverse problem is regularised by means of explicit a priori data. A first-order autoregressive model (e.g. Rodgers, 2000) is used to initialise the a priori covariances of the different quantities and the measurement error covariance, i.e. to describe the spatial and spectral correlations of the a priori data and error data. The covariances are modelled by

$S_{j k}=\sigma_{j} \sigma_{k} \exp \left(-\Delta \nu / c_{\nu}\right) \exp \left(-\Delta z / c_{z}\right)$,

where $\sigma_{j}$ and $\sigma_{k}$ denote the standard deviations of row $j$ and column $k$. Correlations decay exponentially depending on the spectral separation $\Delta v$ between the two windows selected for the retrieval and the vertical distance $\Delta z$ of the tangent heights or atmospheric layers of the individual limb scan, respectively. The strength of the decay is determined by the correlation lengths $c_{v}$ and $c_{z}$. Except for noise, most correlation lengths are not well-known from experimental side and had to be estimated. The values actually used are reported below. The vertical correlation lengths of the a priori data are very important, because they contribute to the smoothing characteristics of the constraint. We discuss this effect in more detail in Sect. 3.6.

When determining the measurement error covariance we do not only consider noise but also include the non-random components (e.g. von Clarmann et al., 2001). In this approach the retrieval results and error analyses are significantly influenced by the spatial and spectral correlations of e.g. uncertainties in radiometric calibration or uncertainties 


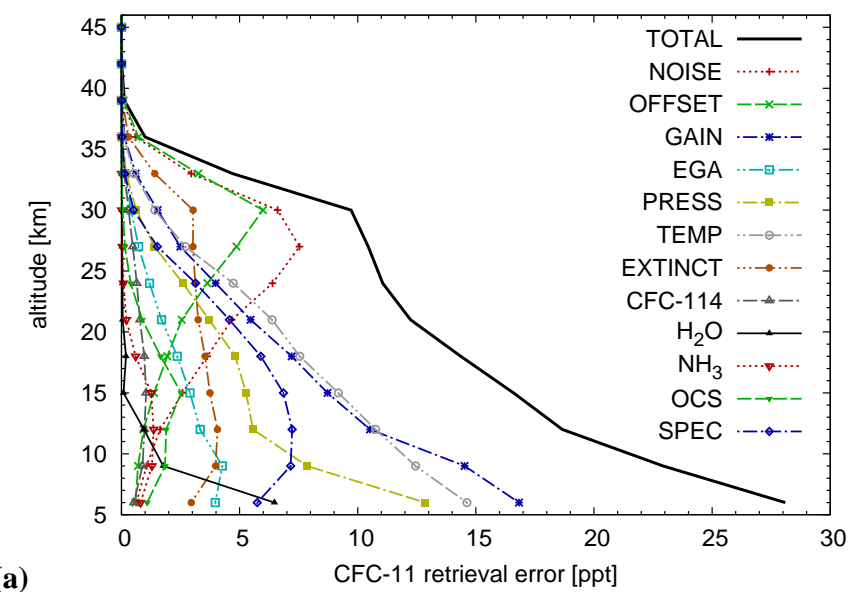

(a)

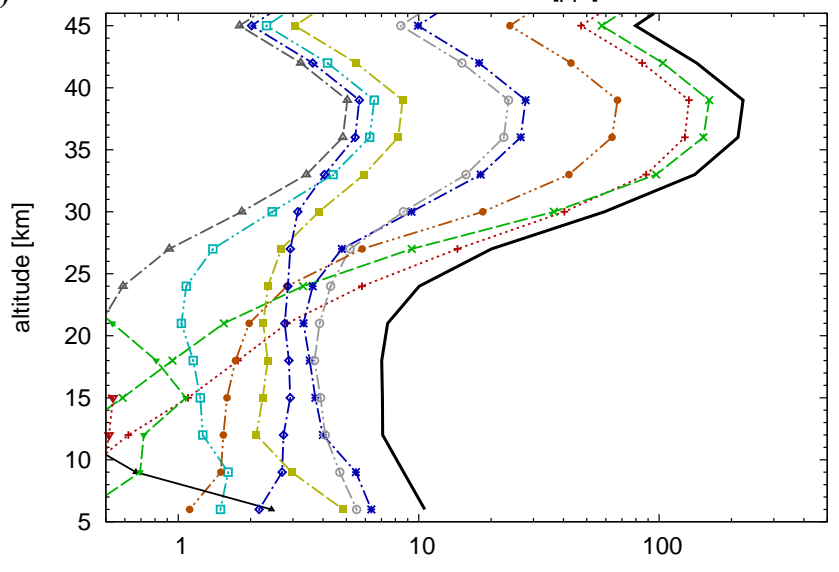

(b)

CFC-11 retrieval error [\%]

Fig. 5. CFC-11 retrieval error budget for mid-latitude atmospheric conditions. Plots show (a) absolute errors and (b) relative errors. Only error sources contributing more than $1 \mathrm{ppt}$ to the CFC-11 retrieval error are shown in the plot. Budgets for other atmospheric conditions are similar.

in model parameters like pressure and temperature. This is a more sophisticated representation of the measurement covariance matrix than used elsewhere. Compared to test retrievals which only consider noise in the measurement covariance, we find substantial differences in the retrieval results at lower altitudes at which noise is a minor source of error. Using the full error covariance increases the amount of a priori information by 5 to $10 \%$, degrades the vertical resolution by about 10 to $20 \%$ and increases the estimated retrieval errors by about 20 to $30 \%$. On the other hand, the negative impact of systematic errors on the retrieval results will be reduced significantly.

The a priori state vector and the parameter vector for the retrieval are prepared by mixing results from the ESA operational retrievals as far as available (see Sect. 2) and data from a climatology prepared for the Envisat MIPAS analysis (Remedios et al., 2007). The RAMstan climatology (Reference Atmospheres for MIPAS, standard atmospheres, version 3.1) was compiled from observations of several experiments aboard the Upper Atmosphere Research Satellite as well as tropospheric and stratospheric chemical transport model output. Climatological data are provided for five different atmospheric conditions (tropics, mid-latitude day or night, polar summer, and polar winter). Mean volume mixing ratios and one sigma variability are reported for more than 30 trace gases. Tropospheric profiles for the source gases are updated to year 2000 estimates where possible. CFC-11 data in the climatology are derived from measurements of the satellite experiment CLAES (Cryogenic Limb Array Etalon Spectrometer) (Roche et al., 1998). The CFC-11 tropospheric volume mixing ratio is set to $265 \mathrm{ppt}$ globally. Climatological data for aerosol extinction coefficients were obtained from 5.26 micron measurements of the Halogen Occultation Experiment (HALOE) (e.g. Hervig et al., 1996). HALOE measurements during the year 2003 were globally averaged to derive an a priori profile. Spectral correction factors for the aerosol extinction are obtained from a Mie-model study.

\subsection{Error analysis}

The error analysis for the retrieval results is based on the concept of linearisation of the transfer function (Rodgers, 1990, 2000). The total retrieval error is composed of (1) direct radiance measurement errors, (2) forward model parameters errors, (3) forward model errors, and (4) smoothing effects due to a priori data. Applying the transfer function concept, detailed error budgets for the CFC-11 retrievals can be estimated. The total retrieval error of the individual CFC-11 volume mixing ratios, including all statistical and systematic components, is typically below $10 \%$ and about 6 to $7 \%$ at best (Table 1, Fig. 5). We will now discuss the individual components of the error budget in more detail.

(1) Direct radiance measurement errors: Noise as well as uncertainties in offset calibration and gain calibration are considered in the error analysis and are all found to make a significant contribution to the budget. The noise equivalent spectral radiance for unapodised spectra is about $30 \mathrm{nW} /\left(\mathrm{cm}^{2} \mathrm{srcm}^{-1}\right.$ ) around 830 to $850 \mathrm{~cm}^{-1}$ (Kleinert et al., 2007). To determine the noise equivalent radiance for the spectral windows selected for the retrieval, a scaling factor $1 / \sqrt{n}$ is applied, where $n$ is the number of grid points within the spectral window. The noise values estimated for the spectral mean radiances are assumed to be uncorrelated between the different spectral windows and different tangent heights. Offset and gain calibration uncertainty were set to $2 \mathrm{nW} /\left(\mathrm{cm}^{2} \mathrm{srcm}^{-1}\right)$ and $2 \%$, respectively (Nett et al., 2002; Kleinert et al., 2007). For the uncertainties in radiometric calibration the spectral correlation length is set to $10 \mathrm{~cm}^{-1}$ and the vertical correlation length is set to $10 \mathrm{~km}$. Sensitivity studies indicate a weak dependence of the estimated retrieval error on the spectral correlation length (over the range from 1 to $100 \mathrm{~cm}^{-1}$ ), but a strong dependence on the vertical correlation length (Hoffmann, 2006). The strongest dependence 
was found for the offset calibration error. The estimated retrieval error varies up to a factor 5 if the offset calibration errors are assumed to be either uncorrelated or fully correlated in altitude.

Other instrumental errors: Spectral instability and shifts as well as uncertainties in the instrument line shape can be neglected considering the wide spectral windows used for the retrieval. These instrumental errors do not significantly alter the spectral mean radiances. Line-of-sight pointing errors are also not considered, as Level-2 tangent heights are a derived data product, i.e. determined from the retrieved pressure and temperature profiles based on the assumption of hydrostatic equilibrium. However, the CFC-11 retrieval error due to uncertainties in pressure and temperature data will be estimated separately. Since the Level-2 tangent heights also depend on the lowermost tangent altitude provided by the Envisat MIPAS attitude data system (i.e. the Level-1B tangent heights) which show rather large daily drifts (of the order of 1 to $2 \mathrm{~km} /$ day), we generally do not use the Level-2 tangent altitudes for further analysis and work with log-pressure altitudes instead. See von Clarmann et al. (2003a) or Kiefer et al. (2007) for a detailed discussion.

(2) Forward model parameter errors and (3) forward model errors: The leading retrieval errors are due to uncertainties in pressure and temperature (set to $3 \%$ and $2 \mathrm{~K}$, respectively, $5 \mathrm{~km}$ vertical correlation length, see Raspollini et al., 2006; Piccolo and Dudhia, 2007), CFC-11 spectroscopic data (set to $3 \%, 10 \mathrm{~km}$ vertical correlation length for a conservative estimate, see Rothman et al., 2003), and spectral shape of the aerosol extinction data (set to $20 \%, 10 \mathrm{~km}$ vertical correlation length, based on a Mie-model study). Retrieval errors caused by uncertainties in minor interfering trace species as well as CFC-11 and aerosol extinction top column data are small or negligible. Forward model errors are mainly due to the approximations used to accelerate the radiative transfer calculations. The retrieval errors due to the forward model errors (set to $0.5 \%, 3 \mathrm{~km}$ vertical correlation length, $10 \mathrm{~cm}^{-1}$ spectral correlation length, see Sect. 3.1) are small compared to other terms.

(4) Smoothing error: The one sigma uncertainties of the CFC-11 climatological data (Remedios et al., 2007) are multiplied by a factor 3 for the retrieval. This approach significantly increases the contribution of measurement information to the retrieval results, but as the a priori uncertainties no longer match the real ensemble, a direct estimate of the smoothing error will be incorrect (Rodgers, 2000). Hence, we generally do not include the smoothing error in the budget. However, for a test retrieval we estimated the smoothing error based on the unscaled a priori covariance. The estimated smoothing error varies in between 6 to $12 \mathrm{ppt}$ ( 3.7 to $5.4 \%$ ). The influence of a priori information on the retrieval results will be discussed in more detail in the following sections.
Table 1. Summary of CFC-11 retrieval errors.

\begin{tabular}{|c|c|c|c|c|c|}
\hline \multirow[t]{2}{*}{$\begin{array}{l}\text { atmospheric } \\
\text { conditions }\end{array}$} & \multirow{2}{*}{$\begin{array}{l}\text { altitude } \\
\text { [km] }\end{array}$} & \multicolumn{2}{|c|}{$\begin{array}{l}\text { noise } \\
\text { error }^{\mathrm{a}}\end{array}$} & \multicolumn{2}{|c|}{$\begin{array}{c}\text { total } \\
\text { error }^{b}\end{array}$} \\
\hline & & [ppt] & {$[\%]$} & [ppt] & {$[\%]$} \\
\hline tropical & 33 & 9 & 27 & 13 & 38 \\
\hline \multirow[t]{9}{*}{ latitudes } & 30 & 10 & 11 & 13 & 15 \\
\hline & 27 & 9 & 6 & 14 & 9 \\
\hline & 24 & 7 & 3 & 15 & 6 \\
\hline & 21 & 5 & 2 & 17 & 6 \\
\hline & 18 & 4 & 2 & 17 & 6 \\
\hline & 15 & 3 & 1 & 17 & 6 \\
\hline & 12 & 2 & 0.6 & 18 & 7 \\
\hline & 9 & 0.9 & 0.3 & 23 & 9 \\
\hline & 6 & 0.8 & 0.3 & 20 & 8 \\
\hline mid- & 30 & 6 & 40 & 10 & 59 \\
\hline \multirow[t]{8}{*}{ latitudes } & 27 & 8 & 14 & 10 & 20 \\
\hline & 24 & 6 & 6 & 11 & 10 \\
\hline & 21 & 5 & 3 & 12 & 7 \\
\hline & 18 & 4 & 2 & 14 & 7 \\
\hline & 15 & 3 & 1 & 17 & 7 \\
\hline & 12 & 2 & 0.6 & 19 & 7 \\
\hline & 9 & 1 & 0.4 & 23 & 9 \\
\hline & 6 & 0.6 & 0.2 & 28 & 11 \\
\hline polar & 27 & 6 & 28 & 9 & 42 \\
\hline \multirow[t]{7}{*}{ summer } & 24 & 6 & 9 & 9 & 14 \\
\hline & 21 & 5 & 4 & 11 & 10 \\
\hline & 18 & 4 & 2 & 13 & 8 \\
\hline & 15 & 3 & 1 & 16 & 7 \\
\hline & 12 & 2 & 0.6 & 18 & 7 \\
\hline & 9 & 1 & 0.4 & 23 & 9 \\
\hline & 6 & 0.8 & 0.3 & 30 & 11 \\
\hline polar & 24 & 5 & 55 & 8 & 87 \\
\hline \multirow[t]{6}{*}{ winter } & 21 & 8 & 27 & 11 & 38 \\
\hline & 18 & 7 & 7 & 11 & 12 \\
\hline & 15 & 5 & 3 & 13 & 8 \\
\hline & 12 & 3 & 1 & 17 & 6 \\
\hline & 9 & 2 & 0.6 & 20 & 8 \\
\hline & 6 & 1 & 0.4 & 26 & 10 \\
\hline
\end{tabular}

a Noise is the only purely statistical error component.

$\mathrm{b}$ The total error reported here excludes the smoothing term.

\subsection{Contribution of a priori information}

The most important diagnostic quantities for characterising the contributions of measurement information versus a priori information to the retrieval results are the averaging kernel matrices derived within the retrieval process. Integrating over the averaging kernels, i.e. the rows of the averaging kernel matrices, gives an approximate estimate of the amount of measurement information in the retrieval result. Subtracting the area from one gives the amount of a priori information. It is important to realize that this approximation is only 


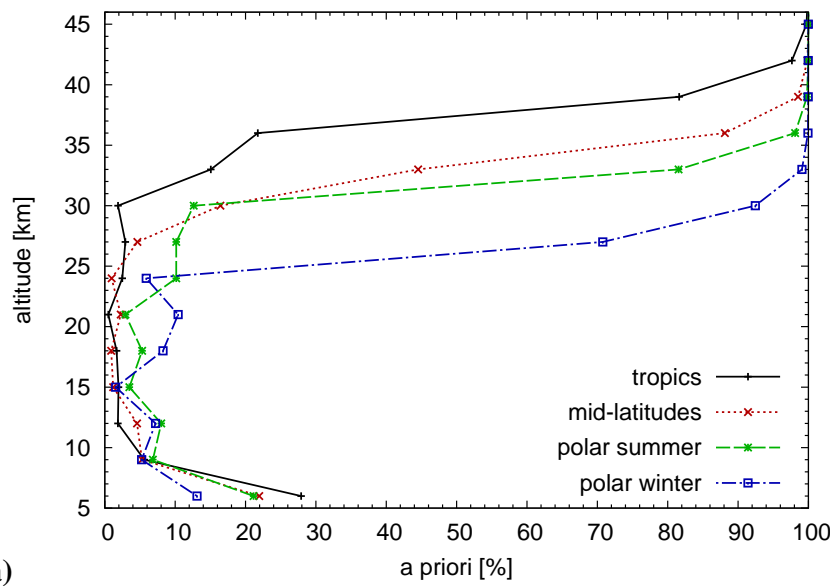

(a)

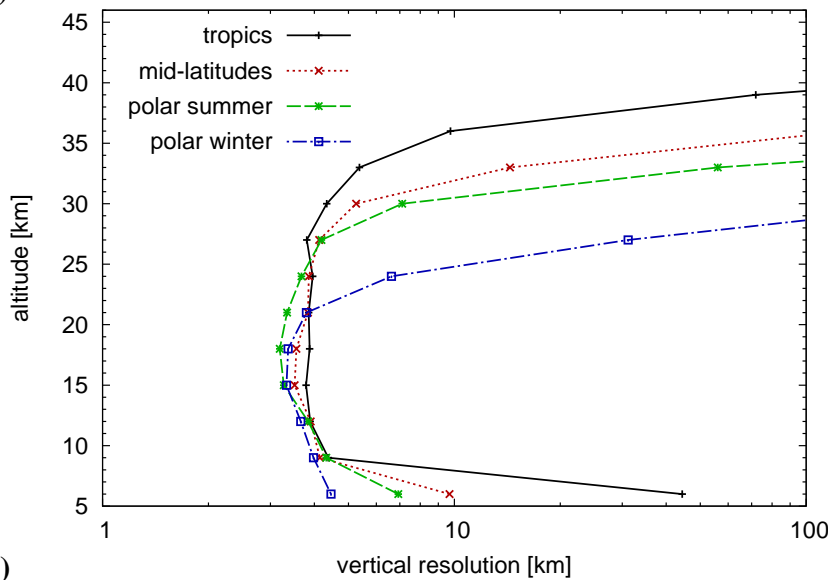

(b)

Fig. 6. (a) Contribution of a priori information to CFC-11 retrieval results and (b) vertical resolution of the observations as derived from the averaging kernel matrices. Curves show results for different atmospheric conditions.

valid for small retrieval errors. For the CFC-11 retrieval, the contribution of a priori information is found to be less than 5 to $10 \%$ when $\mathrm{CFC}-11$ is present in significant concentrations (Fig. 6a). Even if the retrieval result at an atmospheric height level is mainly determined by measurement information, this information must not necessarily originate from the observations at the corresponding tangent height alone, but may also come from adjacent tangent altitudes. This would cause a smoothing effect of the a priori on the retrieved profile. Hence, the vertical resolution of the retrieval needs to be analysed in more detail.

\subsection{Vertical resolution}

An ideal retrieval would exactly reproduce the unknown true atmospheric state. In reality, the retrieval produces a smoothed version of the true trace gas profiles. The averaging kernels take the form of broad maxima rather than delta distributions. Hence, the averaging kernels also describe the resolution of the observations. We applied the concept of in- formation density of Purser and Huang (1993) to estimate the vertical resolution of the $\mathrm{CFC}-11$ retrieval. While the trace of the averaging kernel matrix (i.e. the sum of the diagonal elements) measures the degrees of freedom for signal for the whole profile, the individual diagonal elements measure the degrees of freedom per retrieval grid level. Hence, the reciprocal values of the diagonal elements measure the number of retrieval grid levels per degree of freedom, or the "resolution" of the observations. The reciprocal values have to be multiplied by the retrieval grid spacing (in $[\mathrm{km}]$ ), to get the correct unit. The vertical resolution of the retrieved CFC-11 profiles is about 3 to $4 \mathrm{~km}$ and corresponds to the sampling step of the limb scans and the field of view of the Envisat MIPAS instrument (Fig. 6b).

\section{Validation of the CFC-11 measurements}

\subsection{Internal quality measures}

For the purpose of internal data validation the consistency of the retrieval results with the radiance measurements and the a priori data is checked by applying a standard $\chi^{2}$-test (e.g. Rodgers, 2000) to the final value of the objective function, Eq. (1), for each limb scan. Once the retrieval converged to a solution, the objective function measures the deviations between the actual radiance measurements and the forward model simulations based on the optimal estimate of the state, as well as the deviations between the estimate and the a priori state. The deviations are normalised by the measurement error covariance and the a priori covariance, respectively. The deviations should follow a $\chi^{2}$-distribution with $m$ degrees of freedom. There are $n+m$ measurements, i. e. $m$ radiance data and $n$ a priori data (which are considered as "virtual" measurements), to which $n$ state variables have been fitted.

A normalised $\chi^{2} / m$ around one indicates that the retrieval results are consistent with the measurements and a priori, at least in a statistical sense or for an ensemble of profiles. The $\chi^{2}$-test allows us to identify individual limb scans with abnormally poor fits which are probably not part of the ensemble. In this case the retrieval results and corresponding forward model simulations are either inconsistent with the radiance measurements (with respect to the measurement errors) or inconsistent with the a priori data (with respect to the a priori uncertainty). Since the latter may happen in case of an unusual atmospheric event, the corresponding retrievals are not necessarily "bad" and need to be analysed carefully. However, to prepare the CFC-11 data for subsequent scientific studies, we decided to use a weak filtering criterion and remove only the few extreme outliers. Hence, the individual retrievals are already accepted as successful if the value of the $\chi^{2}$-statistics satisfies the $0.1 \%$ confidence level. This will exclude only $0.1 \%$ of data generated by purely random statistics. 
It is also interesting to study the $\chi^{2} / m$-distribution for a large ensemble of limb scans. A plot of the final $\chi^{2} / \mathrm{m}$ distribution covering all 425000 limb scans of this study is shown in Fig. 7. For comparison the normalised $\chi^{2} / \mathrm{m}$ distribution for the initial guess is shown, too. Since the a priori state is used as initial guess, $\mathbf{x}_{0}=\mathbf{x}_{a}$, this distribution measures only the difference $[\mathbf{y}-\mathbf{F}(\mathbf{x})]^{T} \mathbf{S}_{\epsilon}^{-1}[\mathbf{y}-\mathbf{F}(\mathbf{x})]$ between the radiance measurements and the forward model fit while the difference $\left(\mathbf{x}-\mathbf{x}_{a}\right)^{T} \mathbf{S}_{a}^{-1}\left(\mathbf{x}-\mathbf{x}_{a}\right)$ is identically zero. A peak value around 12 indicates that the initial fits are not consistent with the measurements. The final $\chi^{2} / \mathrm{m}$ distribution indicates that the majority of retrieval results is consistent with the measurements and a priori. However, a peak value near 0.38 indicates that the covariances used are somewhat over-pessimistic. A more detailed analysis shows that both terms of the objective function contribute equally to the observed deviations (distributions peak near 0.17 for the measurements and near 0.15 for the state), i. e. both covariances are affected. Taking into account the more complicated nature of the covariances used in this study we consider the current agreement sufficient. On average only 2.6 iterations are required until the individual retrievals converge. Subtracting one iteration required to detect convergence, this indicates that the particular retrieval problem indeed is a moderately non-linear one.

\subsection{Comparison with other MIPAS retrievals}

The CFC-11 data retrieved with the scheme described in this paper were compared with independent Envisat MIPAS retrievals carried out at the University of Leicester, United Kingdom and the Institut für Meteorologie und Klimaforschung (IMK) at the research centre in Karlsruhe, Germany. These comparisons cannot reveal direct measurement errors of the Envisat MIPAS instrument, but would indicate possible errors in our new forward model and the accompanying retrieval scheme.

Both comparisons with independent retrievals reveal promising results. The comparison with Leicester retrievals confirms that the fast forward model JURASSIC indeed works with sufficient accuracy compared with analyses based on line-by-line forward modelling. In addition, the IMK comparison shows that consistent retrieval results are obtained even if rather different regularisation techniques are applied in the inverse model. The comparisons may indicate that for molecules with broad emission bands like CFC-11 an analysis based on the Envisat MIPAS full spectral resolution radiance measurements will not necessarily improve the retrieval errors. However, the high spectral resolution is essential to study other molecules which can only be detected based on single emission lines.

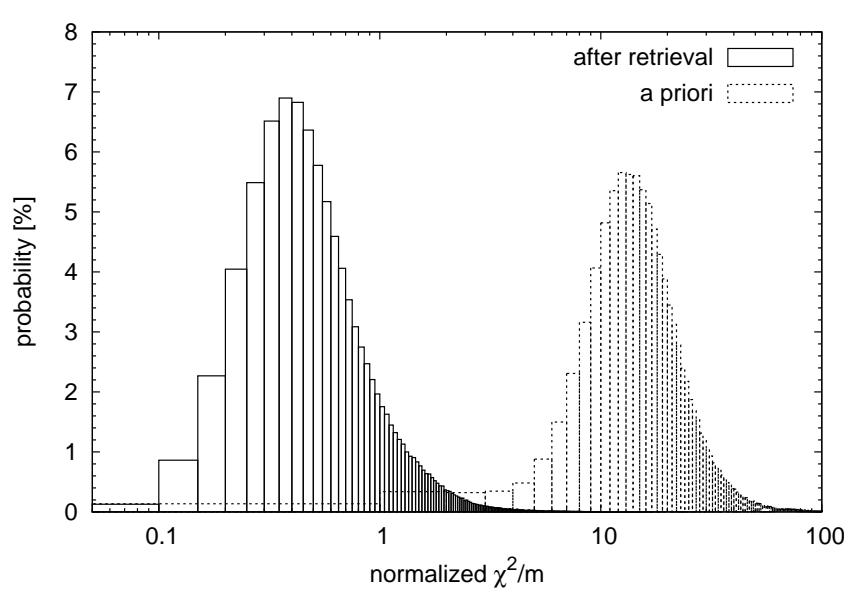

Fig. 7. Probability distribution of normalised objective function values before and after the retrievals were carried out. $\chi^{2}$-values for individual retrievals are normalised by the number $m$ of radiance measurements per limb scan. Bin sizes for the two histograms are 0.05 (after retrieval) and 1 (a priori).

\subsubsection{Comparison with radiometric retrievals}

MIPAS retrievals at the University of Leicester are based on the optimal estimation approach. Similar to the approach presented in this paper, spectral mean radiances rather than detailed spectra are analysed in the Leicester OPERA scheme (Optimal Estimation Retrieval Algorithm) (Moore et al., 2006; Moore and Remedios, 2007) in the inverse model. The MIPAS Reference Forward Model (RFM) is utilised as the forward model. In the OPERA scheme, spectrally averaged radiances are directly obtained from line-by-line calculations while the JURASSIC scheme relies on the emissivity growth approximation.

Since the RFM line-by-line calculations are exact, but time-consuming, the analyses in Leicester are limited to a subset of all available Envisat MIPAS measurements. Comparison between our results here and OPERA results is instructive because it tests the applicability of the fast forward model versus full line-by-line radiative transfer, as well as providing a first verification of algorithm correctness.

There are only minor differences in the retrieval setups, concerning the choice of spectral windows (842.650 to $845.475 \mathrm{~cm}^{-1}$ for CFC-11 in the OPERA scheme) or the initialisation of measurement error covariance and a priori covariance (diagonal matrices in the OPERA scheme, firstorder autoregressive model in this study). The OPERA scheme produces retrieval results for $C I<1.8$, however since the comparison here is for individual matched profiles, in effect the comparison is performed for the $C I<4.0$ threshold.

A direct comparison of about 400 individual scans reveals good agreement (i.e. better than 2 to $3 \%$ ) between JURASSIC results and OPERA results. The differences found in this comparison exceed the estimated 1 to $2 \%$ retrieval errors due 


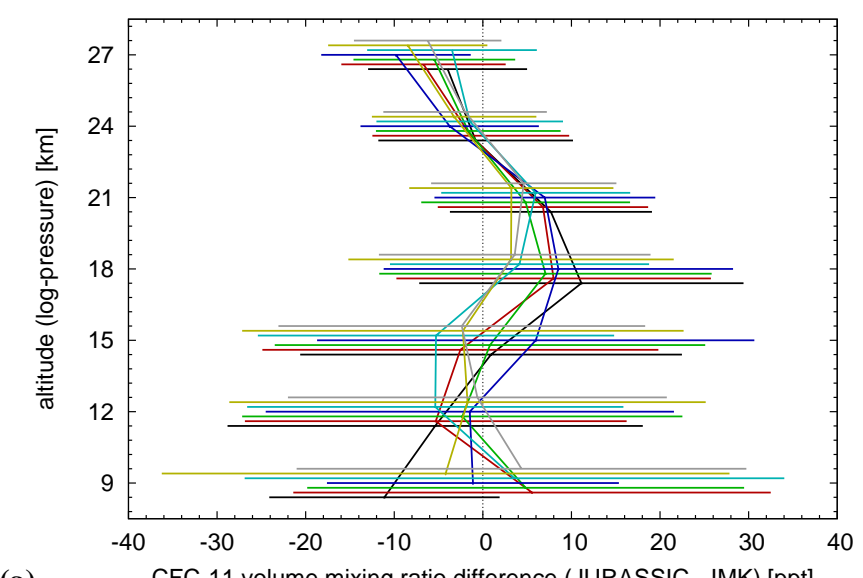

(a)

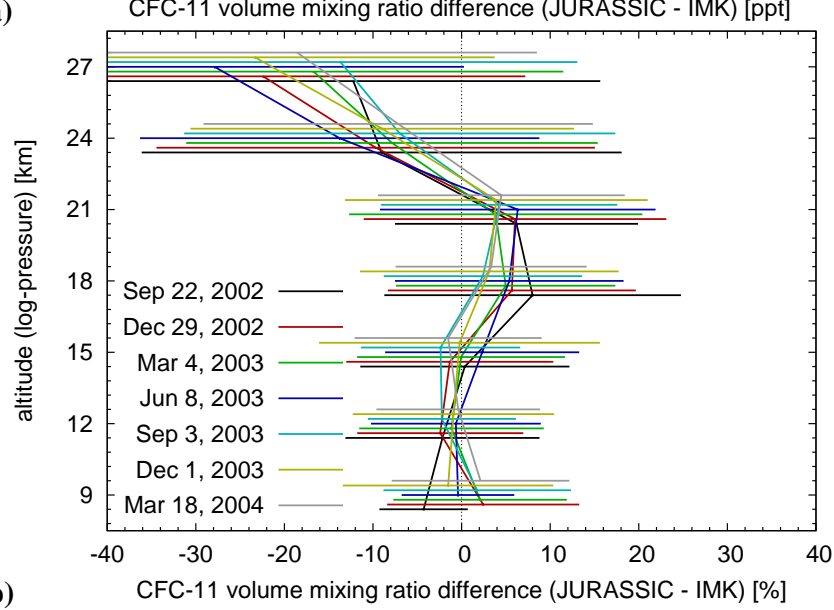

Fig. 8. Comparison of retrieved CFC-11 data with corresponding results obtained at the Institut für Meteorologie und Klimaforschung (IMK), Karlsruhe, Germany. Plots show (a) absolute differences and (b) relative differences. Individual comparisons are based on global datasets for different days (see legend).

to forward model errors (due to the EGA method, compare Fig. 5). However, the rest is likely due to the minor differences in the retrieval setups of the schemes discussed above.

\subsubsection{Comparison with line-by-line retrievals}

The IMK retrievals are based on a regularised global fit approach and the use of the line-by-line radiative transfer model KOPRA (Karlsruhe Optimized and Precise Radiative Transfer Algorithm) (Stiller, 2000; Stiller et al., 2002). Since this approach is rather time consuming, KOPRA has mostly been used for the retrieval of short rather than extended time periods (currently, CFC-11 data are retrieved from about 15\% of all Envisat MIPAS scans). The KOPRA forward model is well validated by cross-comparisons with the RFM as well as several other radiative transfer models (von Clarmann et al., 2003b). A brief description of the IMK CFC-11 retrieval is given by von Clarmann et al. (2007).

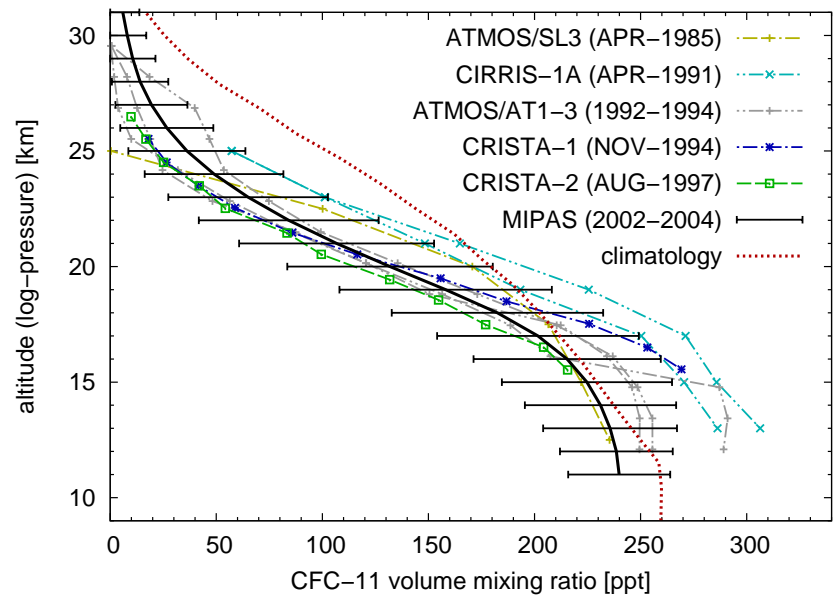

Fig. 9. Comparison of mean CFC-11 vertical profiles from different space experiments. Analysis is restricted to mid-latitude measurements $\left(20\right.$ to $\left.65^{\circ} \mathrm{N} / \mathrm{S}\right)$. Trends are corrected for by mapping all data to the middle of year 2003. For references of data sets see text.

Figure 8 shows a global comparison between our CFC-11 retrieval results and the IMK data (version V3O_F-11_8) for several days. The comparison reveals small systematic differences of about -6 to $6 \mathrm{ppt}$ ( -9 to $5 \%$ below $25 \mathrm{~km}$ ). Standard deviations are in the range of 8 to $24 \mathrm{ppt}$ ( 9 to $23 \%$ ). A direct comparison indicates good to perfect agreement for many CFC-11 profiles. However, some profiles show large differences. Possible reasons to explain these differences are uncertainties in temperature and pressure, tangent altitudes, abundances of interfering species (ESA operational data versus IMK data), as well as different approaches for the retrieval of radiometric background caused by aerosols and for the regularisation of the retrieval problem. These aspects have to be addressed in future work, but are out of the scope of this paper.

\subsection{Comparison with other satellite experiments}

Figure 9 shows a comparison between mean CFC-11 vertical profiles from different space experiments and corresponding Envisat MIPAS data. Comparisons are carried out with measurements from ATMOS (Atmospheric Trace Molecule Spectroscopy) (Zander et al., 1992, http://remus. jpl.nasa.gov/atmos), CIRRIS-1A (Cryogenic Infrared Radiance Instrumentation for Shuttle) (Bingham et al., 1997) and CRISTA (Cryogenic Infrared Spectrometers and Telescopes for the Atmosphere) (Offermann et al., 1999; Riese et al., 1999b; Grossmann et al., 2002). Trends are corrected for in this comparison by mapping all profiles to the middle of the year 2003, i.e. the mid point of the MIPAS measurement period. Profiles are mapped considering global tropospheric trend data derived from ground-based network measurements (Blake, 2005) and age of air data (Waugh and Hall, 2002). Generally, good agreement is found between the 
results of the different experiments. The shape of the mean profiles is nearly identical in all cases. Small offsets may be explained by systematic measurement errors, data sampling issues, or remaining uncertainties in trend correction.

The individual CFC-11 measurements of ATMOS have a high accuracy and precision, i.e. uncertainties are below 5\% (Gunson et al., 1996). However, we see more variability in the mean profiles. This is due to the limited number of measurements and the irregular latitudinal and temporal distribution of the solar occultation measurements. The CRISTA1 measurements (November 1994) show a steeper gradient than the MIPAS measurements in the lower stratosphere. However, the corresponding retrievals are influenced by a high aerosol radiance background below $20 \mathrm{~km}$, caused by the eruption of the volcano Pinatubo in June 1991 (P. Preusse, personal communication, Spang et al., 2002). The CRISTA2 profile (measurements in July 1997) corresponds better with the remaining measurements and shows a nearly identical stratospheric gradient to that seen in the MIPAS data. The climatological data from Remedios et al. (2007) shown in Fig. 9 deviate significantly from all other measurements (i.e. about 2 to 3 climatological standard deviations). The climatological data are based on measurements from the satellite experiment CLAES (Cryogenic Limb Array Etalon Spectrometer) (Roche et al., 1998). These measurements, obtained during the years 1991 to 1993 are likely to be even more influenced by the Pinatubo aerosols than the CRISTA1 measurements. A similar Pinatubo effect for CFC-12 has been shown by Remedios et al. (2007). However, the direct comparison shows that the Envisat MIPAS retrieval results are not or only slightly influenced by the deficits of the climatology, which is used as a priori in our retrieval setup.

\subsection{Comparison with air-borne in-situ measurements}

The retrieved MIPAS CFC-11 data were compared with measurements from the High Altitude Gas Analyzer (HAGAR) (Riediger et al., 2000) aboard the high-altitude research aircraft M-55 Geophysica. HAGAR measures trace gas concentrations with a gas chromatograph. The HAGAR measurements shown in Fig. 10 were obtained during a validation campaign for Envisat MIPAS in March 2003 near Kiruna, Sweden $\left(68^{\circ} \mathrm{N}, 21^{\circ} \mathrm{E}\right)$ (Baehr et al., 2004). The scatter of individual measurements is due to atmospheric variability rather than instrument noise or other errors. The uncertainty of the individual HAGAR measurements is about $1 \%$. During the validation campaign the flight track of the Geophysica aircraft was oriented such that the in-situ aircraft instruments sampled the same air volume as Envisat MIPAS, i.e. misstime and miss-distance are minimised. The direct comparison of the HAGAR and MIPAS measurements shows good agreement of the CFC-11 data. Differences are below 5 to $10 \%$ for the two flights.
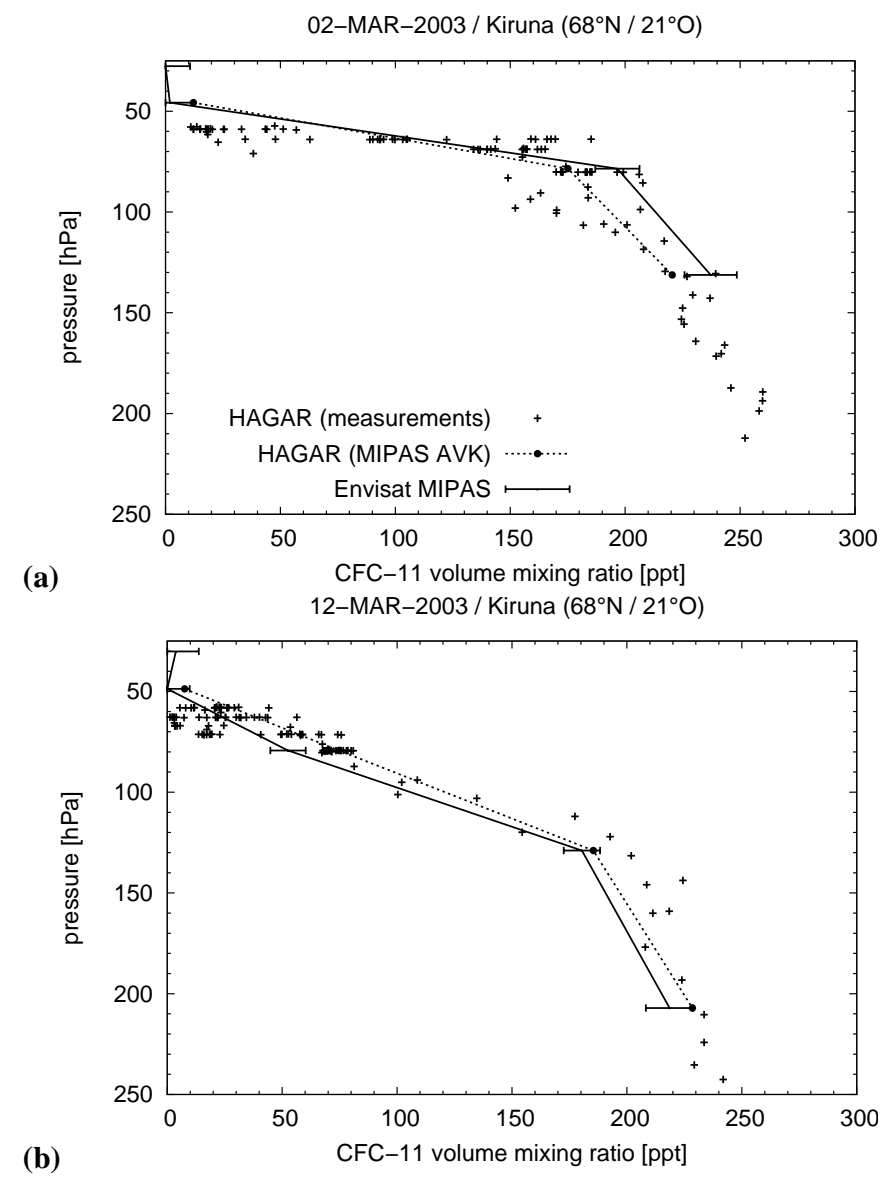

Fig. 10. Comparison of two individual MIPAS CFC-11 vertical profiles (solid curves) and corresponding in-situ measurements of the instrument HAGAR (plus symbols). HAGAR mean profiles (dotted curves) are corrected for smoothing effects of the Envisat MIPAS averaging kernels. Measurements were taken during two validation flights of the high-altitude research aircraft M-55 Geophysica near Kiruna, Sweden in March 2003.

\subsection{Comparison with ground-based measurements}

The tropospheric concentrations of CFC-11 are monitored by several networks of ground-based measurement stations. During the year 2003 the global mean tropospheric volume mixing ratio of CFC-11 was in between 254.9 to $257.3 \mathrm{ppt}$ and the growth rate was in between -1.0 to $-0.7 \%$ year (WMO, 2007). The global mean tropospheric volume mixing ratio derived from the Envisat MIPAS measurements is $(243 \pm 17)$ ppt, which is about 12 to $14 \mathrm{ppt}(5 \%)$ lower than the global mean from the ground based measurements. However, this difference remains within the estimated systematic errors of the individual Envisat MIPAS measurements (compare Fig. 5). Please note that this comparison might be biased because the polar troposphere is not regularly covered by our analysis. 
Table 2. Climatological compilation of Envisat MIPAS CFC-11 data.

\begin{tabular}{|c|c|c|c|c|c|c|c|c|}
\hline \multirow{2}{*}{$\begin{array}{c}\text { altitude } \\
{[\mathrm{km}]}\end{array}$} & \multicolumn{2}{|c|}{$\begin{array}{l}\text { tropical } \\
\text { latitudes }\end{array}$} & \multicolumn{2}{|c|}{$\begin{array}{l}\text { mid- } \\
\text { latitudes }\end{array}$} & \multicolumn{2}{|c|}{$\begin{array}{c}\text { polar } \\
\text { summer }\end{array}$} & \multicolumn{2}{|c|}{$\begin{array}{l}\text { polar } \\
\text { winter }\end{array}$} \\
\hline & $\begin{array}{c}\text { mean } \\
{[\mathrm{ppt}]}\end{array}$ & $\begin{array}{c}\text { sigma } \\
{[\mathrm{ppt}]}\end{array}$ & $\begin{array}{c}\text { mean } \\
{[\mathrm{ppt}]}\end{array}$ & $\begin{array}{c}\text { sigma } \\
{[\mathrm{ppt}]}\end{array}$ & $\begin{array}{l}\text { mean } \\
{[\mathrm{ppt}]}\end{array}$ & $\begin{array}{c}\text { sigma } \\
{[\mathrm{ppt}]}\end{array}$ & $\begin{array}{l}\text { mean } \\
{[\mathrm{ppt}]}\end{array}$ & $\begin{array}{c}\text { sigma } \\
{[\mathrm{ppt}]}\end{array}$ \\
\hline 34 & 5 & 8 & - & - & - & - & - & - \\
\hline 33 & 7 & 9 & - & - & - & - & - & - \\
\hline 32 & 11 & 10 & - & - & - & - & - & - \\
\hline 31 & 15 & 12 & 6 & 8 & - & - & - & - \\
\hline 30 & 22 & 14 & 8 & 9 & - & - & - & - \\
\hline 29 & 32 & 17 & 11 & 11 & 4 & 5 & - & - \\
\hline 28 & 46 & 21 & 14 & 13 & 6 & 6 & - & - \\
\hline 27 & 67 & 22 & 19 & 17 & 9 & 7 & - & - \\
\hline 26 & 94 & 24 & 27 & 22 & 12 & 8 & - & - \\
\hline 25 & 121 & 27 & 36 & 28 & 16 & 9 & 13 & 16 \\
\hline 24 & 148 & 27 & 49 & 33 & 22 & 10 & 18 & 20 \\
\hline 23 & 172 & 26 & 65 & 38 & 29 & 13 & 23 & 24 \\
\hline 22 & 193 & 25 & 84 & 42 & 39 & 17 & 33 & 28 \\
\hline 21 & 208 & 21 & 107 & 46 & 54 & 22 & 46 & 33 \\
\hline 20 & 219 & 17 & 132 & 48 & 72 & 29 & 62 & 39 \\
\hline 19 & 227 & 15 & 158 & 50 & 95 & 38 & 83 & 45 \\
\hline 18 & 233 & 14 & 183 & 50 & 119 & 47 & 108 & 48 \\
\hline 17 & 236 & 14 & 202 & 48 & 143 & 53 & 134 & 50 \\
\hline 16 & 238 & 15 & 215 & 44 & 167 & 52 & 159 & 51 \\
\hline 15 & 241 & 16 & 225 & 40 & 187 & 46 & 182 & 49 \\
\hline 14 & 246 & 16 & 231 & 36 & 203 & 40 & 202 & 45 \\
\hline 13 & 249 & 14 & 236 & 32 & 213 & 33 & 215 & 40 \\
\hline 12 & - & - & 239 & 27 & 223 & 25 & - & - \\
\hline 11 & - & - & 240 & 24 & - & - & - & - \\
\hline
\end{tabular}

\section{Compilation of CFC-11 climatological data}

\subsection{Latitudinal distribution}

We compiled the CFC-11 data retrieved from the Envisat MIPAS measurements during the period July 2002 to March 2004 to provide an update for the climatology of Remedios et al. (2007). Hence, the individual measurements were sorted into four groups. The "tropical latitudes" include all measurements in the latitude range $20^{\circ} \mathrm{S}$ to $20^{\circ} \mathrm{N}$. The "mid-latitudes" cover all measurements in the latitude ranges $20^{\circ} \mathrm{N}$ to $65^{\circ} \mathrm{N}$ and $65^{\circ} \mathrm{S}$ to $20^{\circ} \mathrm{S}$. The "polar summer" and "polar winter" groups cover all measurements north of $65^{\circ} \mathrm{N}$ or south of $65^{\circ} \mathrm{S}$ during the months January to March and October to December or April to September, respectively. For each case we report the CFC-11 mean volume mixing ratio and the one-sigma variability on a $1 \mathrm{~km}$ log-pressure altitude grid (Table 2, Fig. 11). We only report the data if statistics are based on at least 25000 individual measurements.

Individual CFC-11 volume mixing ratios are not taken into account in this analysis if they contain more than $10 \%$ a priori information. The contribution of a priori information to the retrieval results are derived from the averaging kernel data (see Sect. 3.5). The filtering removes all observations where the volume mixing ratios drop below $\approx 5 \mathrm{ppt}$. In this case the radiance signal is low compared to the measurement errors and does not provide sufficient information for the retrieval. Filtering also removes all altitudes where the MIPAS line-ofsight was obscured by clouds and the retrieval result corresponds to the a priori data. Selecting a strict threshold of $10 \%$ for the maximum amount of a priori information ensures that the bias in the averaged profiles due to neglected trends in the a priori data is less than 0.5 to $1 \%$ (Hoffmann et al., 2005).

\subsection{Seasonal variability}

The time series of CFC-11 mean volume mixing ratio and corresponding variability shown in Fig. 12 illustrate in more detail the atmospheric variability captured in the 21 months of nearly continuous Envisat MIPAS measurements. CFC11 is upwelling from the troposphere into the stratosphere mainly at tropical latitudes. Accordingly, the time series 

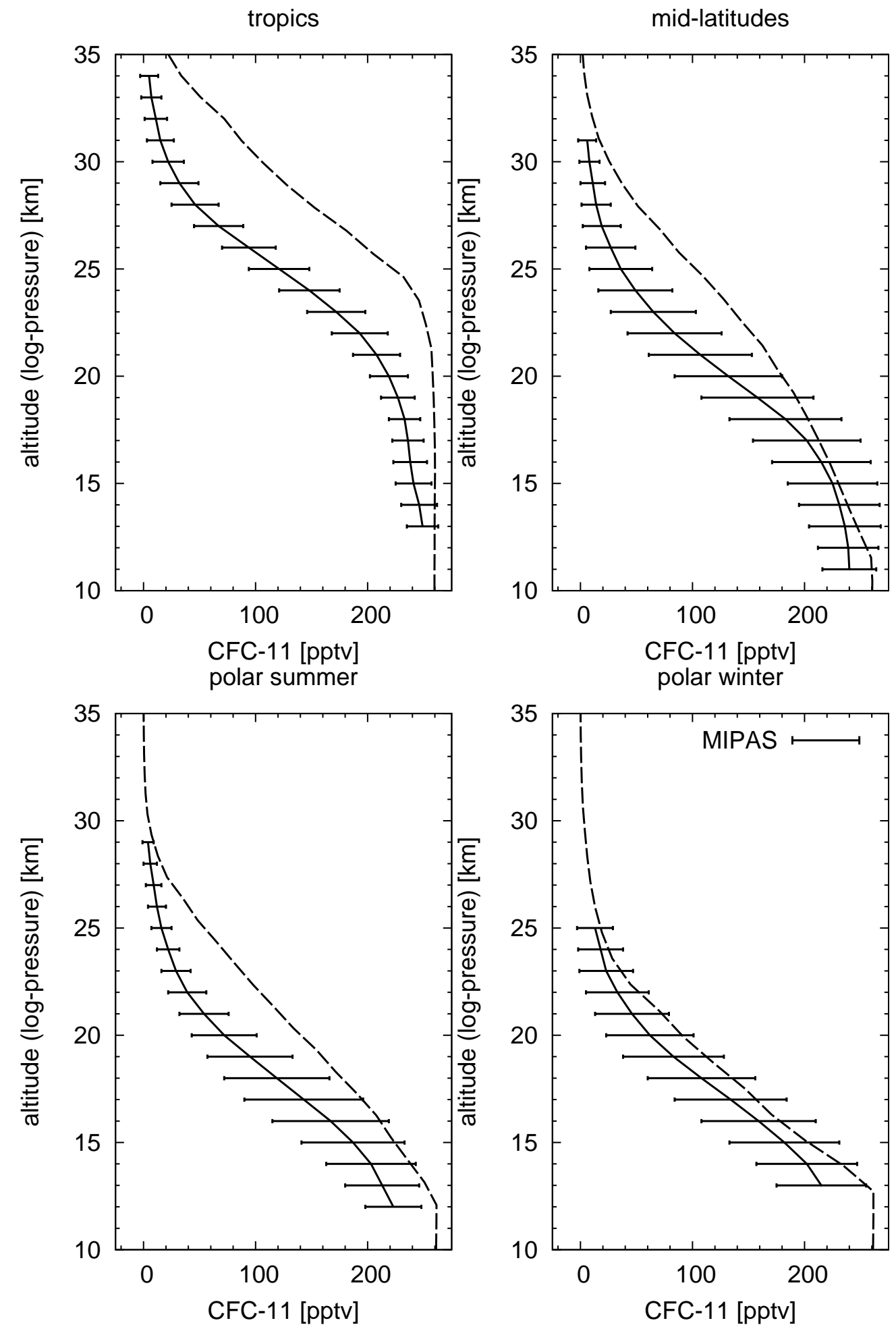

Fig. 11. Comparison of CFC-11 climatological data compiled from Envisat MIPAS measurements during July 2002 to March 2004 and corresponding data provided by Remedios et al. (2007) based on CLAES satellite measurements (projected to the mid of the year 2003 using global tropospheric trend data and age of air data). Plots are for different atmospheric conditions (see plot titles). 
$659 \mathrm{~N}$ to $90^{\circ} \mathrm{N}$
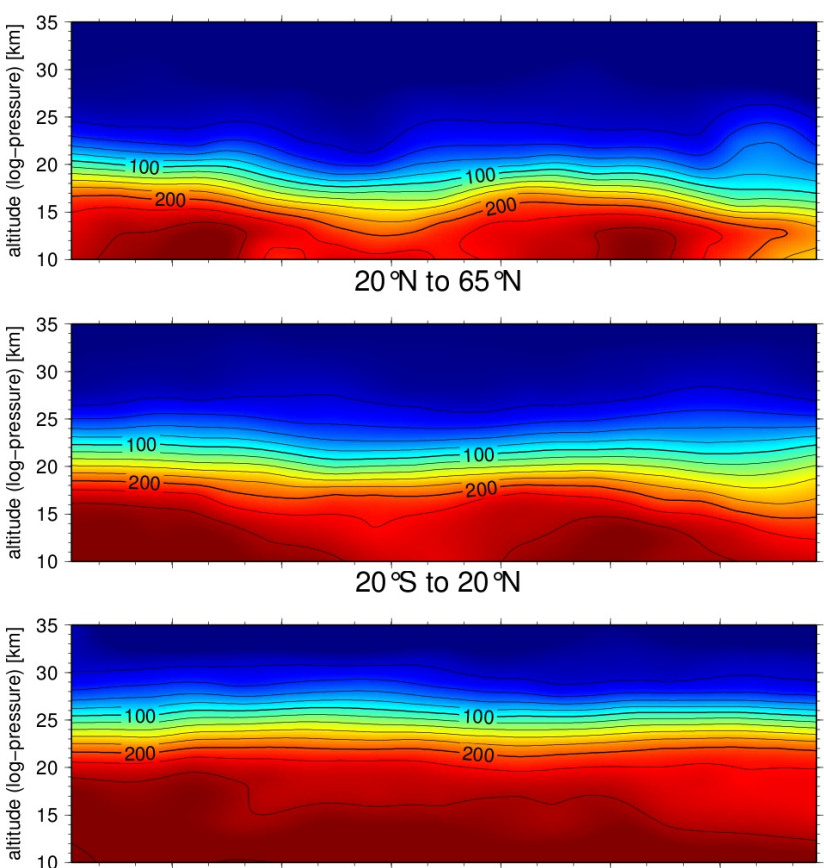

$65^{\circ} \mathrm{S}$ to $20^{\circ} \mathrm{S}$

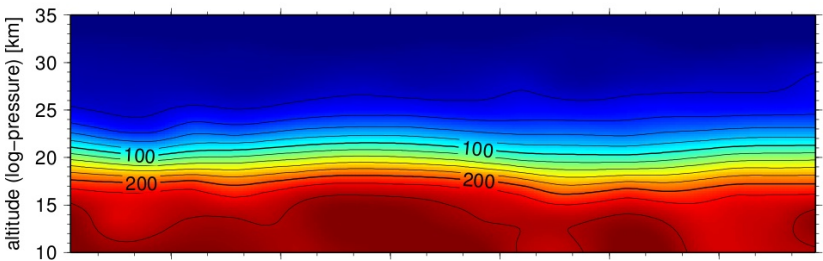

$90^{\circ} \mathrm{S}$ to $65^{\circ} \mathrm{S}$

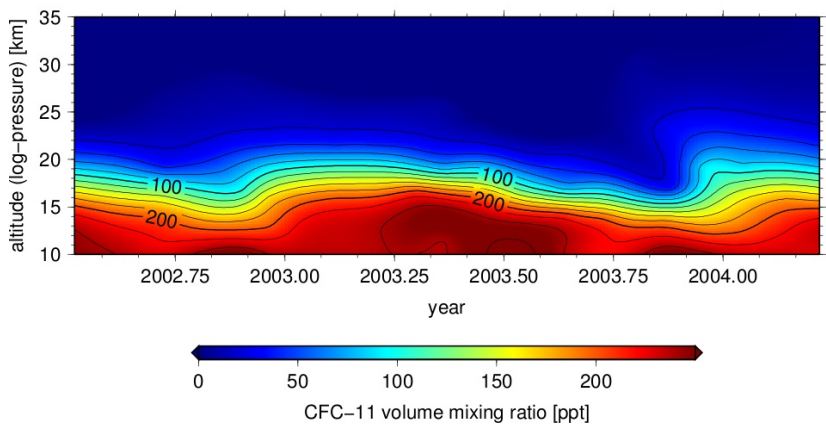

$65^{\circ} \mathrm{N}$ to $90^{\circ} \mathrm{N}$
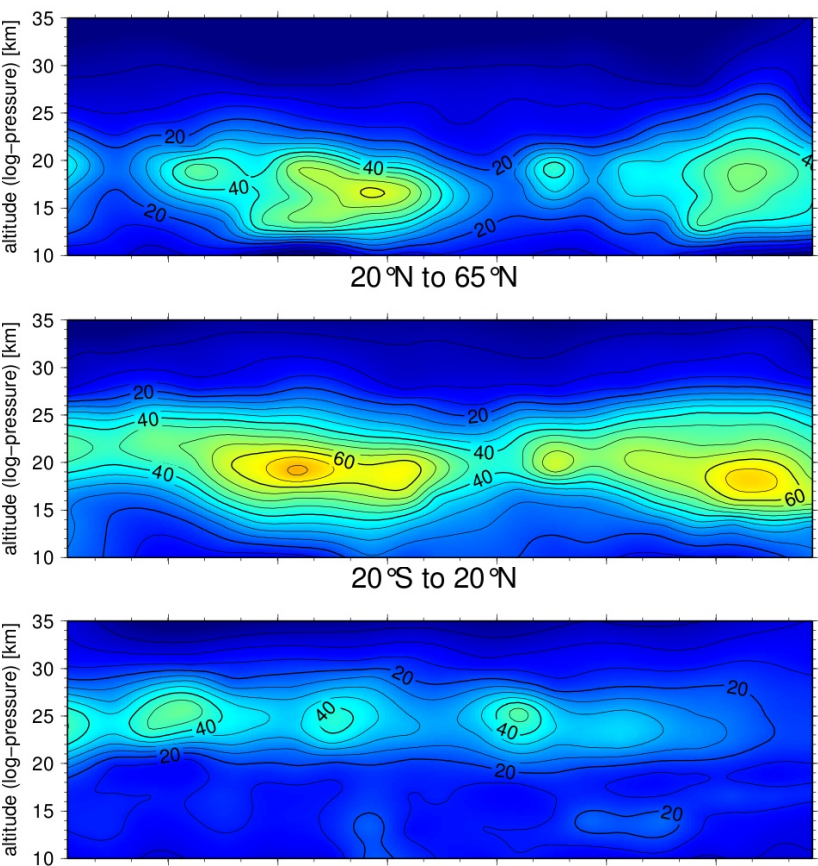

$65^{\circ} \mathrm{S}$ to $20^{\circ} \mathrm{S}$

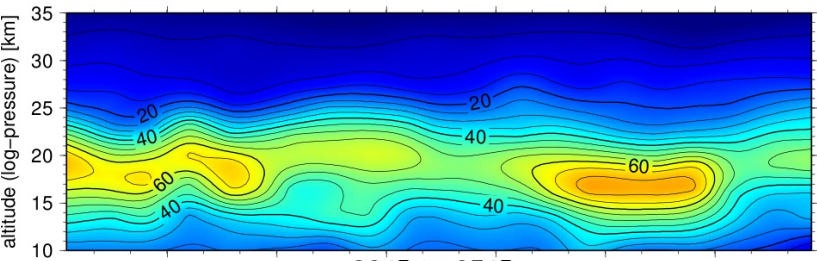

$90^{\circ} \mathrm{S}$ to $65^{\circ} \mathrm{S}$
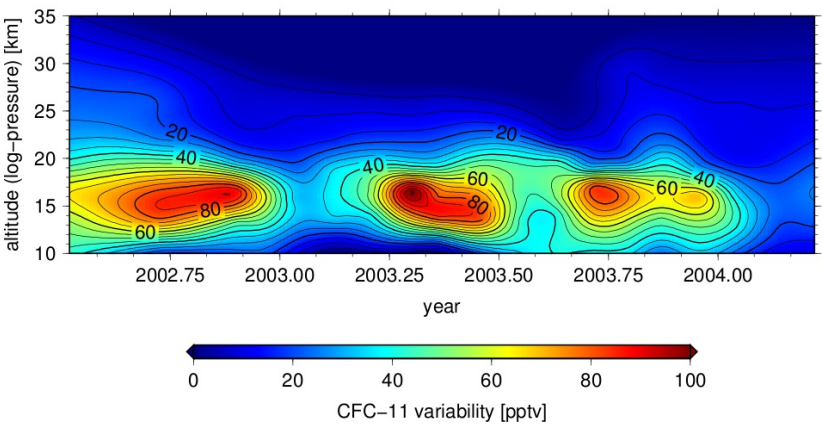

Fig. 12. Time series of CFC-11 mean volume mixing ratio (left column) and corresponding one-sigma variability (right column). Envisat MIPAS data has been averaged on a monthly base for five latitude bands (see plot titles).

for tropical latitudes shows the highest average concentrations. In the stratosphere tropical air masses are driven to higher latitudes by the residual mean circulation and largescale eddy transport. However, CFC-11 is destroyed by photolytical decomposition and concentrations decrease with increasing altitudes. At polar latitudes the CFC-11 abundances decrease especially in the winter months due to subsidence of air masses in the polar vortex. This effect is more pronounced in the southern polar winter hemisphere due to the more stable polar vortex. The rather rapid increase in mean CFC-11 abundance at south polar latitudes in late spring (November/December 2003 and November/December 2004) indicates very strong mixing of mid-latitude and polar air masses when the polar vortex breaks down. 
The CFC-11 variability is lowest at tropical latitudes. During the two year period a maximum monthly variability of 40 to $50 \mathrm{ppt}$ was seen around $25 \mathrm{~km}$ altitude. The variability increases towards mid and polar latitudes due to increased mixing of $\mathrm{CFC}-11$ rich tropical air masses and $\mathrm{CFC}-11$ poor polar air masses by planetary wave activity. The CFC-11 variability reaches up to 60 to $70 \mathrm{ppt}$ around 15 to $20 \mathrm{~km}$ altitude. The highest variabilities are found in the winter months, i.e. during November to April in the Northern Hemisphere and August to December in the Southern Hemisphere. A hemispheric difference in variability can be observed at polar latitudes. A maximum CFC-11 variability up to 90 to $100 \mathrm{ppt}$ is found at south polar latitudes, which is about twice the variability of the north polar latitudes. This enhanced variability is most likely due to the more stable vortex in the Southern Hemisphere and much stronger gradients of CFC11 across the vortex boundary. The enhanced variability in the Southern Hemisphere is mainly due to the activity of the planetary wave-1, i.e. the vortex is shifted away from the pole and crosses the $65^{\circ} \mathrm{S}$ latitude boundary used to define the south polar region.

Reports on CFC-11 variance are rather rare and comparisons are often difficult. However, in a comparison of Envisat MIPAS CFC-11 variability for August 2003 and measurements of the CRISTA-2 satellite experiment in August 1997 we found excellent agreement (Kuell et al., 2004; Hoffmann, 2006). This gives confidence that both satellite experiments are capable of capturing the atmospheric variability on synoptic and planetary scales. However, the Envisat MIPAS time series presented here provide additional information about the seasonal dependence over a period of nearly two years.

\section{Conclusions}

Envisat MIPAS radiance measurements are well-suited to retrieving the global distribution of CFC-11 in the upper troposphere and lower stratosphere. Utilising a newly developed rapid radiative transfer model and an accompanying optimal estimation retrieval processor we analysed more than 425000 Envisat MIPAS limb scans measured in the time period from July 2002 to March 2004. The total error of the retrieved CFC-11 volume mixing ratios is typically below $10 \%$ in our retrieval scheme. The retrieval error is dominated by noise and offset calibration errors at upper altitudes and uncertainties of temperature data and gain calibration data at lower altitudes. Retrieval errors due to the use of the rapid approximative forward model are rather small. Retrieval results typically contain less than 5 to $10 \%$ a priori information. The vertical resolution of the observations is about 3 to $4 \mathrm{~km}$. Several validation activities, i.e. internal quality measures, comparison with other satellite measurements, an air-borne in-situ instrument, and ground-based measurements, suggest that the retrieved CFC-11 data are reliable.
We compiled all retrieved data to provide a new climatology of CFC-11 for four climatological cases (tropical latitudes, mid-latitudes, polar summer and polar winter). The new climatology shows significantly lower CFC-11 abundances in the lower stratosphere compared with data provided in the RAMstan V3.1 climatology. The observed differences are up to 45 to $150 \%$ at 19 to $27 \mathrm{~km}$ altitude. The new climatological data set will be provided as an electronic supplement to this paper http://www.atmos-chem-phys.net/ 8/3671/2008/acp-8-3671-2008-supplement.zip. Time series of CFC-11 mean abundance and variability for five latitude bands were derived from the measurements and can be explained by the residual mean circulation and large-scale eddy-transports in the upper troposphere and lower stratosphere. CFC-11 variability is strongly influenced by the planetary wave activity near the boundary of the polar vortex. The new CFC-11 data set has a great potential for model validation and case studies of transport and mixing processes in the upper troposphere and lower stratosphere on synoptic or planetary scales and up to the inter-seasonal time scale. It is well suited for further scientific studies.

Acknowledgements. Envisat MIPAS data was provided by the European Space Agency (Cat-1 project 2515). We thank A. Dudhia, University of Oxford, United Kingdom, for providing the MIPAS Reference Forward Model. We thank A. Grimsdell, NWRA/CoRA, Boulder, CO, United States, for comments on the manuscript.

Edited by: R. MacKenzie

\section{References}

Baehr, J., Volk, C. M., Ivanova, E., Werner, A., Wetter, T., Engel, A., Haase, H.-P., Möbius, T., Schmidt, U., Stiller, G., von Clarmann, T., Glatthor, N., Kellmann, S., Grunow, K., and Levin, I.: Validation of MIPAS-Envisat $\mathrm{CH}_{4}, \mathrm{~N}_{2} \mathrm{O}, \mathrm{CFC}-11$ and CFC-12 by airborne in situ observations, in: Proceedings of the 2004 Envisat \& ERS Symposium, ESA SP-572, Salzburg, Austria, 2004.

Bingham, G. E., Zhou, D. K., Bartschi, B. Y., Anderson, G. P., Smith, D. R., Chetwynd, J. H., and Nadile, R. M.: Cryogenic Infrared Radiance Instrumentation for Shuttle (CIRRIS 1A) Earth limb spectral measurements, calibration, and atmospheric $\mathrm{O}_{3}$, $\mathrm{HNO}_{3}$, CFC-12, and CFC-11 profile retrieval, J. Geophys. Res., 102, 3547-3558, 1997.

Blake, D.: Methane, Nonmethane Hydrocarbons, Alkyl Nitrates, and Chlorinated Carbon Compounds including 3 Chlorofluorocarbons (CFC-11, CFC-12, and CFC-113) in Whole-air Samples, in: Trends: A Compendium of Data on Global Change, Tech. rep., Carbon Dioxide Information Analysis Center, Oak Ridge National Laboratory, US Department of Energy, Oak Ridge, Tenn., USA, 2005.

Blake, N. J., Blake, D. R., Simpson, I. J., Lopez, J. P., Johnston, N. A. C., Swanson, A. L., Katzenstein, A. S., Meinardi, S., Sieve, B. C., Colman, J. J., Atlas, E., Flocke, F., Vay, S. A., Avery, M. A., and Rowland, F. S.: Large-scale latiduinal and vertical distributions of NMHCs and selected halocarbons in the troposphere over the Pacific Ocean during the March-April 1999 Pa- 
cific Exploratory Mission (PEM-Tropics B), J. Geophys. Res., 106, 32 627-32 644, 2001.

Carli, B., Alpaslan, D., Carlotti, M., Castelli, E., Ceccherini, S., Dinelli, B. M., Dudhia, A., Flaud, J. M., Höpfner, M., Jay, V., Magnani, L., Oelhaf, H., Payne, V., Piccolo, C., Prosperi, M., Raspollini, P., Remedios, J., Ridolfi, M., and Spang, R.: First results of MIPAS/ENVISAT with operational Level 2 code, Adv. Space Res., 33, 1012-1019, 2004.

Carlotti, M., Höpfner, M., Raspollini, P., and Ridolfi, M.: MIPAS Level 2 Algorithm Theoretical Baseline Document, Tech. Rep. TN-IROE-RSA9601, Istituto di Ricerca sulle Onde Elettromagnetiche Nello Carrara (IROE), Firenze, Italy, 2001.

Coheur, P. F., Clerbaux, C., and Colin, R.: Spectroscopic measurements of halocarbons and hydrohalocarbons by satelliteborne remote sensors, J. Geophys. Res., 108(D4), 4130, doi:10.1029/2002JD002649, 2003.

Dubock, P. A., Spoto, F., Simpson, J., Spencer, D., Schutte, E., and Sontag, H.: The Envisat Satellite and Its Integration, ESA Bull., 106, 26-45, 2001.

Dudhia, A.: RFM Software User's Manual, Department of Atmospheric, Oceanic and Planetary Physics, University of Oxford, United Kingdom, http://www.atm.ox.ac.uk/RFM, 2004.

Dudhia, A., Jay, V. L., and Rodgers, C. D.: Microwindow selection for high-spectral-resolution sounders, Appl. Optics, 41, 36653673, 2002.

Elkins, J. W., Fahey, D. W., Gilligan, J. M., Dutton, G. S., Baring, T. J., Volk, C. M., Dunn, R. E., Myers, R. C., Montzka, S. A., Wamsley, P. R., Hayden, A. H., Butler, J. H., Thompson, T. M., Swanson, T. H., Dlugokencky, E. J., Novelli, P. C., Hurst, D. F., Lobert, J. M., Ciciora, S. J., McvLaughlin, R. J., Thompson, T. L., Winkler, R. H., Fraser, P. J., Steele, L. P., and Lucarelli, M. P.: Airborne gas chromatograph for in situ measurements of long-lived species in the upper troposphere and lower stratosphere, Geophys. Res. Lett., 23, 347-350, 1996.

Endemann, M.: MIPAS Instrument Concept and Performance, in: Proceedings of ESAMS '99 - European Symposium on Atmospheric Measurements from Space, 29-43, 1999.

Fischer, H. and Oelhaf, H.: Remote sensing of vertical profiles of atmospheric trace constituents with MIPAS limb-emission spectrometers, Appl. Optics, 35, 2787-2796, 1996.

Fischer, H., Birk, M., Blom, C., Carli, B., Carlotti, M., von Clarmann, T., Delbouille, L., Dudhia, A., Ehhalt, D., Endemann, M., Flaud, J. M., Gessner, R., Kleinert, A., Koopmann, R., Langen, J., Lpez-Puertas, M., Mosner, P., Nett, H., Oelhaf, H., Perron, G., Remedios, J., Ridolfi, M., Stiller, G., and Zander, R.: MIPAS: an instrument for atmospheric and climate research, Atmos. Chem. Phys., 8, 2151-2188, 2008,

http://www.atmos-chem-phys.net/8/2151/2008/.

Francis, G. L., Edwards, D. P., Lambert, A., Halvorson, C. M., Lee-Taylor, J. M., and Gille, J. C.: Forward modeling and radiative transfer for the NASA EOS-Aura High Resolution Dynamics Limb Sounder (HIRDLS) instrument, J. Geophys. Res., 111, D13301, doi:10.1029/2005JD006270, 2006.

Glatthor, N., von Clarmann, T., Fischer, H., Funke, B., Gil-López, S., Grabowski, U., Höpfner, M., Kellmann, S., Linden, A., López-Puertas, M., Tsidu, G. M., Milz, M., Steck, T., Stiller, G. P., and Wang, D.-Y.: Retrieval of stratospheric ozone profiles from MIPAS/ENVISAT limb emission spectra: a sensitivity study, Atmos. Chem. Phys., 6, 2767-2781, 2006, http://www.atmos-chem-phys.net/6/2767/2006/.

Golombek, A. and Prinn, R. G.: A global three-dimensional model of the circulation and chemistry of $\mathrm{CFCl}_{3}, \mathrm{CF}_{2} \mathrm{Cl}_{2}, \mathrm{CH}_{3} \mathrm{CCl}_{3}$, $\mathrm{CCl}_{4}$ and $\mathrm{N}_{2} \mathrm{O}$, J. Geophys. Res., 91, 3985-4001, 1986.

Gordley, L. L. and Russel, J. M.: Rapid inversion of limb radiance data using an emissivity growth approximation, Appl. Optics, 20, 807-813, 1981.

Grossmann, K. U., Offermann, D., Gusev, O., Oberheide, J., Riese, M., and Spang, R.: The CRISTA-2 mission, J. Geophys. Res., 107(D23), 8173, doi:10.1029/2001JD000667, 2002.

Gunson, M. R., Abbas, M. M., Abrams, M. C., Allen, M., Brown, L. R., Brown, T. L., Chang, A. Y., Goldman, A., Irion, F. W., Lowes, L. L., Mahieu, E., Manney, G. L., Michelsen, H. A., Newchurch, M. J., Rinsland, C. P., Salawitch, R. J., Stiller, G. P., Toon, G. C., Yung, Y. L., and Zander, R.: The Atmospheric Trace Molecule Spectroscopy (ATMOS) experiment: Deployment on the ATLAS Space Shuttle missions, Geophys. Res. Lett., 23, 2333-2336, 1996.

Hartley, D. E., Kindler, T., Cunnold, D. M., and Prinn, R. G.: Evaluating chemical transport models: Comparison of effects of different CFC-11 emission scenarios, J. Geophys. Res., 101, $14381-$ 14385, 1996.

Hervig, M. E., Russell III, J. M., Gordley, L. L., Park, J. H., Drayson, S. R., and Deshler, T.: Validation of aerosol measurements from the Halogen Occultation Experiment, J. Geophys. Res., 101, 10 267-10 276, 1996.

Hoffmann, L.: Schnelle Spurengasretrieval für das Satellitenexperiment Envisat MIPAS, Tech. Rep. JUEL-4207, Forschungszentrum Jülich, Germany, ISSN 0944-2952, 2006.

Hoffmann, L., Spang, R., Kaufmann, M., and Riese, M.: Retrieval of CFC-11 and CFC-12 from Envisat MIPAS observations by means of rapid radiative transfer calculations, Adv. Space Res., 36, 915-921, 2005.

IPCC: Climate Change 2007: The Physical Science Basis. Contributions of Working Group I to the Fourth Assessment Report of the Intergovernmental Panel on Climate Change, Cambridge University Press, 2007.

Kao, C.-Y., Tie, J. X., Mroz, E., Cunnold, D., and Alyea, F.: Simulations of the global CFC-11 using the Los Alamos chemical tracer model, J. Geophys. Res., 95, 15 827-15 838, 1992.

Kiefer, M., von Clarmann, T., Grabowski, U., Laurentis, M. D., Mantovani, R., Milz, M., and Ridolfi, M.: Characterization of MIPAS elevation pointing, Atmos. Chem. Phys., 7, 1615-1628, 2007, http://www.atmos-chem-phys.net/7/1615/2007/.

Kleinert, A., Aubertin, G., Perron, G., Birk, M., Wagner, G., Hase, F., Nett, H., and Poulin, R.: MIPAS Level 1B algorithms overview: operational processing and characterization, Atmos. Chem. Phys., 7, 1395-1406, 2007, http://www.atmos-chem-phys.net/7/1395/2007/.

Kuell, V., Olschewski, F., Jarisch, M., Offermann, D., and Grossmann, K. U.: Trace gas variability in the stratosphere, Adv. Space Res., 34, 1722-1730, 2004.

Kuell, V., Offermann, D., Jarisch, M., Schaeler, B., Engel, A., Claude, G., Smit, H. G. J., Ebel, A., and Feldmann, H.: Tropopause region temperatures and CFC 11 mixing ratios from CRISTA 2, J. Geophys. Res., 110, D16104, doi:10.1029/2004JD005592, 2005.

Lachance, R. L.: MIPAS Level 1B Algorithm Technical Baseline 
Document: An Overview, in: Proceedings of ESAMS '99 - European Symposium on Atmospheric Measurements from Space, 51-63, 1999.

Louet, J.: The Envisat Mission and System, ESA Bull., 106, 11-25, 2001.

Marshall, B. T., Gordley, L. L., and Chu, D. A.: BANDPAK: Algorithms for Modeling Broadband Transmission and Radiance, J. Quant. Spectrosc. Radiat. Transfer, 52, 581-599, 1994.

McDaniel, A. H., Cantrell, C. A., Davidson, J. A., Shetter, R. E., and Calvert, J. C.: The Tenperature Dependent, Infrared Absorption Cross-Sections for the Chlorofluorocarbons: CFC-11, CFC-12, CFC-13, CFC-14, CFC-22, CFC-113, CFC-114, and CFC-115, J. Atmos. Chem., 12, 211-227, 1991.

Moore, D. P. and Remedios, J. J.: Growth rates of stratospheric HCFC-22, Atmos. Chem. Phys., 8, 73-82, 2008,

http://www.atmos-chem-phys.net/8/73/2008/.

Moore, D. P., Waterfall, A. M., and Remedios, J. J.: The potential for radiometric retrievals of halocarbon concentrations from the MIPAS-E instrument, Adv. Space Res., 37, 2238-2246, 2006.

Morgenstern, O., Lee, A. M., and Pyle, J. A.: Cumulative mixing inferred from stratospheric tracer relationships, J. Geophys. Res., 107, 8321, doi:10.1029/2002JD002098, 2002 (printed 108(D5), 2003).

Müller, R., McKenna, D. S., Schmidt, U., Engel, A., and Proffitt, M. H.: The $\mathrm{O}_{3}-\mathrm{N}_{2} \mathrm{O}$ relation from balloon-borne observations as a measure of Arctic ozone loss in 1991/92, Q. J. Roy. Meteorol. Soc., 127, 1389-1412, 2001.

Nett, H.: MIPAS Data Products, in: Proceedings of ESAMS '99 - European Symposium on Atmospheric Measurements from Space, pp. 45-49, 1999.

Nett, H., Perron, G., Sanchez, M., Burgess, A., and Mosner, P.: MIPAS In-Flight Calibration and Processor Verification, in: Proceedings of the Envisat Calibration Review, SP-520, ESA Publications Division, ESTEC, Keplerlaan 1, 2200 AG Noordwijk, The Netherlands, 2002.

Norton, R. H. and Beer, R.: New apodizing functions for Fourier spectrometry, J. Opt. Soc. Am., 66, 259-264, see errata, 1976.

Norton, R. H. and Beer, R.: Errata for 'New apodizing functions for Fourier spectrometry', J. Opt. Soc. Am., 67, 419, 1977.

Notholt, J.: FTIR measurements of $\mathrm{HF}, \mathrm{N}_{2} \mathrm{O}$ and CFCs during the Arctic polar night with the moon as light source, subsidence during winter 1992/93, Geophys. Res. Lett., 21, 2385-2388, 1994.

Offermann, D., Grossmann, K.-U., Barthol, P., Knieling, P., Riese, M., and Trant, R.: Cryogenic Infrared Spectrometers and Telescopes for the Atmosphere (CRISTA) experiment and middle atmosphere variability, J. Geophys. Res., 104, 16311-16325, 1999.

Piccolo, C. and Dudhia, A.: Precision validation of MIPAS-Envisat products, Atmos. Chem. Phys., 7, 1915-1923, 2007, http://www.atmos-chem-phys.net/7/1915/2007/.

Plumb, R. A., Waugh, D. W., and Chipperfield, M. P.: The effects of mixing on tracer relationships in the polar vortices, J. Geophys. Res., 105, 10 047-10 062, 2000.

Prinn, R. G., Weiss, R. F., Fraser, P. J., Simmonds, P. G., Cunnold, D. M., Alyea, F. N., O’Doherty, S., Salameh, P., Miller, B. R., Huang, J., Wang, R. H. J., Hartley, D. E., Harth, C., Steele, L. P., Sturrock, G., Midgley, P. M., and McCulloch, A.: A history of chemically and radiatively important gases in air deduced from ALE/GAGE/AGAGE, J. Geophys. Res., 105,
17 751-17 792, 2000.

Purser, R. J. and Huang, H.-L.: Estimating Effective Data Density in a Satellite Retrieval or an Objective Analysis, J. Appl. Meteor., 32, 1092-1107, 1993.

Raspollini, P., Belotti, C., Burgess, A., Carli, B., Carlotti, M., Ceccherini, S., Dinelli, B. M., Dudhia, A., Flaud, J.-M., Funke, B., Höpfner, M., López-Puertas, M., Payne, V., Piccolo, C., Remedios, J. J., Ridolfi, M., and Spang, R.: MIPAS level 2 operational analysis, Atmos. Chem. Phys., 6, 5605-5630, 2006,

http://www.atmos-chem-phys.net/6/5605/2006/.

Remedios, J. J., Leigh, R. J., Waterfall, A. M., Moore, D. P., Sembhi, H., Parkes, I., Greenhough, J., Chipperfield, M., and Hauglustaine, D.: MIPAS reference atmospheres and comparisons to V4.61/V4.62 MIPAS level 2 geophysical data sets, Atmos. Chem. Phys. Discuss., 7, 9973-10 017, 2007.

Ridolfi, M., Carli, B., Carlotti, M., von Clarmann, T., Dinelli, B. M., Dudhia, A., Flaud, J.-M., Höpfner, M., Morris, P. E., Raspollini, P., Stiller, G., and Wells, R. J.: Optimized forward model and retrieval scheme for MIPAS near-real-time data processing, Appl. Optics, 39, 1323-1340, 2000.

Ridolfi, M., Blum, U., Carli, B., Catoire, V., Ceccherini, S., Claude, H., Clercq, C. D., Fricke, K. H., Friedl-Vallon, F., Iarlori, M., Keckhut, P., Kerridge, B., Lambert, J.-C., Meijer, Y. J., Mona, L., Oelhaf, H., Pappalardo, G., Pirre, M., Rizi, V., Robert, C., Swart, D., von Clarmann, T., Waterfall, A., and Wetzel, G.: Geophysical validation of temperature retrieved by the ESA processor from MIPAS/ENVISAT atmospheric limb-emission measurements, Atmos. Chem. Phys., 7, 4459-4487, 2007, http://www.atmos-chem-phys.net/7/4459/2007/.

Riediger, O., Volk, C. M., Strunk, M., and Schmidt, U.: HAGAR - A new in situ tracer instrument for stratospheric balloons and high altitude aircraft, Eur. Comm. Air Pollut. Res. Report, 73, 727-730, 2000.

Riese, M., Spang, R., Preusse, P., Ern, M., Jarisch, M., Offermann, D., and Grossmann, K. U.: Cryogenic Infrared Spectrometers and Telescopes for the Atmosphere (CRISTA) data processing and atmospheric temperature and trace gas retrieval, J. Geophys. Res., 104, 16349-16367, 1999a.

Riese, M., Tie, X., Brasseur, G., and Offermann, D.: Threedimensional simulation of stratospheric trace gas distributions measured by CRISTA, J. Geophys. Res., 104, 16419-16435, 1999b.

Roche, A. E., Nightingale, R. W., Kumer, J. B., Mergenthaler, J. L., Jackman, C. H., and Fleming, E. L.: Distribution and seasonal variation of CFCs in the stratosphere: Comparison of satellite global data and a 2-D model, Adv. Space Res., 21, 1383-1391, 1998.

Rodgers, C. D.: Retrieval of Atmospheric Temperature and Composition From Remote Measurements of Thermal Radiation, Rev. Geophys. Space Phys., 14, 609-624, 1976.

Rodgers, C. D.: Characterization and Error Analysis of Profiles Retrieved From Remote Sounding Measurements, J. Geophys. Res., 95, 5587-5595, 1990.

Rodgers, C. D.: Information Content and Optimizitaion of High Spectral Resolution Remote Measurements, Adv. Space Res., 21, 361-367, 1998.

Rodgers, C. D.: Inverse Methods for Atmospheric Sounding: Theory and Practice, vol. 2 of "Series on Atmospheric, Oceanic and Planetary Physics”, World Scientific, 2000. 
Rothman, L. S., Barbe, A., Benner, D. C., Brown, L. R., CamyPeyret, C., Carleer, M. R., Chance, K., Clerbaux, C., Dana, V., Devi, V. M., Fayt, A., Flaud, J.-M., Gamache, R. R., Goldman, A., Jacquemart, D., Jucks, K. W., Lafferty, W. J., Mandin, J.Y., Massie, S. T., Nemtchinov, V., Newnham, D. A., Perrin, A., Rinsland, C. P., Schroeder, J., Smith, K. M., Smith, M. A. H., Tang, K., Toth, R. A., Auwera, J. V., Varanasi, P., and Yoshino, K.: The HITRAN Molecular Spectroscopic Database: Edition of 2000 Including Updates through 2001, J. Quant. Spectrosc. Radiat. Transfer, 82, 5-44, 2003.

Solomon, S.: Stratospheric ozone depletion: A review of concepts and history, Rev. Geophys., 37, 275-316, 1999.

Spang, R., Eidmann, G., Riese, M., Offermann, D., Preusse, P., Pfister, L., and Wang, P.-H.: CRISTA observations of cirrus clouds around the tropopause, J. Geophys. Res., 107(D23), 8174, doi:10.1029/2001JD000698, 2002.

Spang, R., Remedios, J. J., and Barkley, M. P.: Colour indices for the detection and differentiation of cloud type in infra-red limb emission spectra, Adv. Space Res., 33, 1041-1047, 2004.

Stiller, G. P.: The Karlsruhe Optimized and Precise Radiative Transfer Algorithm (KOPRA), Tech. Rep. FZKA-6487, Forschungszentrum Karlsruhe, 2000.

Stiller, G. P., von Clarmann, T., Funke, B., Glatthor, N., Hase, F., Höpfner, M., and Linden, A.: Sensitivity of trace gas abundances retrievals from infrared limb emission spectra to simplifying approximations in radiative transfer modelling, Appl. Optics, 41, 249-280, 2002.

Varansi, P.: Absorption coefficients of CFC-11 and CFC-12 needed for atmospheric remote sensing and global warming studies, J. Quant. Spectrosc. Radiat. Transfer, 48, 205-219, 1991.

von Clarmann, T. and Echle, G.: Selection of optimized microwindows for atmospheric spectroscopy, Appl. Optics, 37, 76617669, 1998.

von Clarmann, T., Grabowski, U., and Kiefer, M.: On the role of non-random errors in inverse problems in radiative transfer and other applications, J. Quant. Spectrosc. Radiat. Transfer, 71, 3946, 2001.

von Clarmann, T., Glatthor, N., Grabowski, U., Höpfner, M., Kellmann, S., Kiefer, M., Linden, A., Tsidu, G. M., Milz, M., Steck, T., Stiller, G. P., Wang, D. Y., and Fischer, H.: Retrieval of temperature and tangent altitude pointing from limb emission spectra recorded from space by the Michelson Interferometer for Passive Atmospheric Sounding (MIPAS), J. Geophys. Res., 108(D23), 4736, doi:10.1029/2003JD003602, 2003a. von Clarmann, T., Höpfner, M., Funke, B., López-Puertas, M., Dudhia, A., Jay, V., Schreier, F., Ridolfi, M., Ceccherini, S., Kerridge, B., Reburn, J., and Siddans, R.: Modelling of atmospheric midinfrared radiative transfer: the AMIL2DA algorithm intercomparison experiment, J. Quant. Spectrosc. Radiat. Transfer, 78, 381-407, 2003b.

von Clarmann, T., Glatthor, N., Stiller, G. P., Grabowski, U., Höpfner, M., Kellmann, S., Linden, A., Milz, M., Steck, T., Fischer, H., Funke, B., and Koukouli, M. E.: MIPAS measurements of upper tropospheric $\mathrm{C}_{2} \mathrm{H}_{6}$ and $\mathrm{O}_{3}$ during the Southern hemispheric biomass burning season in 2003, Atmos. Chem. Phys., 7, 5861-5872, 2007, http://www.atmos-chem-phys.net/7/5861/2007/.

Waugh, D. W. and Hall, T. M.: Age of Stratospheric Air: Theory, Observations, and Models, Rev. Geophys., 40(4), 1010, doi:10.1029/2000RG000101, 2002.

Waugh, D. W., Hall, T. M., and Haine, T. W. N.: Relationships among tracer ages, J. Geophys. Res., 108(C5), 3138, doi:10.1029/2002JC001325, 2003.

Weinreb, M. P. and Neuendorffer, A. C.: Method to Apply Homogeneous-path Transmittance Models to Inhomogenous Atmospheres, J. Atmos. Sci., 30, 662-666, 1973.

WMO: Scientific Assessment of Ozone Depletion: 2006, Global Ozone Research and Monitoring Project - Report No. 50, Geneva, Switzerland, 2007.

Yokota, T., Nakajima, H., Sugita, T., Tsubaki, H., Itou, Y., Kaji, M., Suzuki, M., Kanzawa, H., Park, J. H., and Sasano, Y.: Improved Limb Atmospheric Spectrometer (ILAS) data retrieval algorithm for Version 5.20 gas profile products, J. Geophys. Res., 107(D24), 8216, doi:10.1029/2001JD000628, 2002.

Zander, R., Gunson, M. R., Farmer, C. B., Rinsland, C. P., Irion, F. W., and Mahieu, E.: The 1985 Chlorine and Fluorine Inventories in the Stratosphere Based on ATMOS Observations at $30^{\circ}$ North Latitude, J. Atmos. Chem., 15, 171-186, 1992.

Zander, R., Mahieu, E., Gunson, M. R., Abrams, M. C., Chang, A. Y., Abbas, M., Aellig, C., Engel, A., Goldman, A., Irion, F. W., Kämpfer, N., Michelsen, H. A., Newchurch, M. J., Rinsland, C. P., Salawitch, R. J., Stiller, G. P., and Toon, G. C.: The 1994 northern midlatitude budget of stratospheric chlorine derived from ATMOS/ATLAS-3 observations, Geophys. Res. Lett., 23, 2357-2360, 1996. 